\title{
A seasonal study of dissolved cobalt in the Ross Sea, Antarctica: micronutrient behavior, absence of scavenging, and relationships with $\mathrm{Zn}, \mathrm{Cd}$, and $\mathrm{P}$
}

\author{
M. A. Saito ${ }^{1}$, T. J. Goepfert ${ }^{1}$, A. E. Noble ${ }^{1}$, E. M. Bertrand ${ }^{1}$, P. N. Sedwick ${ }^{2}$, and G. R. DiTullio ${ }^{3}$ \\ ${ }^{1}$ Marine Chemistry and Geochemistry Department, Woods Hole Oceanographic Institution, Woods Hole, MA 02543, USA \\ ${ }^{2}$ Old Dominion University, Department of Ocean, Earth and Atmospheric Sciences, Norfolk, VA 23529, USA \\ ${ }^{3}$ College of Charleston, Hollings Marine Laboratory, 331 Fort Johnson, Charleston, SC 29412, USA
}

Received: 30 July 2010 - Published in Biogeosciences Discuss.: 25 August 2010

Revised: 1 December 2010 - Accepted: 9 December 2010 - Published: 22 December 2010

\begin{abstract}
We report the distribution of cobalt (Co) in the Ross Sea polynya during austral summer 2005-2006 and the following austral spring 2006. The vertical distribution of total dissolved $\mathrm{Co}(\mathrm{dCo})$ was similar to soluble reactive phosphate $\left(\mathrm{PO}_{4}^{3-}\right)$, with dCo and $\mathrm{PO}_{4}^{3-}$ showing a significant correlation throughout the water column $\left(r^{2}=0.87,164\right.$ samples). A strong seasonal signal for dCo was observed, with most spring samples having concentrations ranging from $\sim 45-85 \mathrm{pM}$, whereas summer dCo values were depleted below these levels by biological activity. Surface transect data from the summer cruise revealed concentrations at the low range of this seasonal variability $(\sim 30 \mathrm{pMdCo})$, with concentrations as low as $20 \mathrm{pM}$ observed in some regions where $\mathrm{PO}_{4}^{3-}$ was depleted to $\sim 0.1 \mu \mathrm{M}$. Both complexed Co, defined as the fraction of $\mathrm{dCo}$ bound by strong organic ligands, and labile Co, defined as the fraction of dCo not bound by these ligands, were typically observed in significant concentrations throughout the water column. This contrasts the depletion of labile Co observed in the euphotic zone of other ocean regions, suggesting a much higher bioavailability for Co in the Ross Sea. An ecological stoichiometry of $37.6 \mu \mathrm{mol} \mathrm{Co:}$ $\mathrm{mol}^{-1} \mathrm{PO}_{4}^{3-}$ calculated from dissolved concentrations was similar to values observed in the subarctic Pacific, but approximately tenfold lower than values in the Eastern Tropical Pacific and Equatorial Atlantic. The ecological stoichiometries for dissolved Co and $\mathrm{Zn}$ suggest a greater overall use of $\mathrm{Zn}$ relative to Co in the shallow waters of the Ross Sea, with a Co: $\mathrm{PO}_{4}^{3-} / \mathrm{Zn}: \mathrm{PO}_{4}^{3-}$ ratio of 1:17. Comparison of these ob-
\end{abstract}

served stoichiometries with values estimated in culture studies suggests that $\mathrm{Zn}$ is a key micronutrient that likely influences phytoplankton diversity in the Ross Sea. In contrast, the observed ecological stoichiometries for Co were below values necessary for the growth of eukaryotic phytoplankton in laboratory culture experiments conducted in the absence of added zinc, implying the need for significant $\mathrm{Zn}$ nutrition in the $\mathrm{Zn}$-Co cambialistic enzymes. The lack of an obvious kink in the dissolved $\mathrm{Co}: \mathrm{PO}_{4}^{3-}$ relationship was in contrast to $\mathrm{Zn}: \mathrm{PO}_{4}^{3-}$ and $\mathrm{Cd}: \mathrm{PO}_{4}^{3-}$ kinks previously observed in the Ross Sea. An excess uptake mechanism for kink formation is proposed as a major driver of $\mathrm{Cd}: \mathrm{PO}_{4}^{3-}$ kinks, where $\mathrm{Zn}$ and $\mathrm{Cd}$ uptake in excess of that needed for optimal growth occurs at the base of the euphotic zone, and no clear Co kink occurs because its abundances are too low for excess uptake. An unusual characteristic of Co geochemistry in the Ross Sea is an apparent lack of Co scavenging processes, as inferred from the absence of dCo removal below the euphotic zone. We hypothesize that this vertical distribution reflects a low rate of Co scavenging by Mn oxidizing bacteria, perhaps due to Mn scarcity, relative to the timescale of the annual deep winter mixing in the Ross Sea. Thus Co exhibits nutrient-like behavior in the Ross Sea, in contrast to its hybrid-type behavior in other ocean regions, with implications for the possibility of increased marine Co inventories and utility as a paleooceanographic proxy. 


\section{Introduction}

The Ross Sea is a region of considerable biological and geochemical interest due to its intense annual phytoplankton bloom and associated carbon export (Arrigo et al., 1998; DiTullio et al., 2000). The sea overlies a continental shelf adjacent to the Antarctic continent and is mostly covered by sea ice in the austral winter. Seasonal melting forms the Ross Sea Polynya, which typically opens to the Southern Ocean in late summer. The seasonal phytoplankton bloom in the Ross Sea Polynya is the largest such feature in the Southern Ocean, and typically consists of an initial Phaeocystis antarctica bloom followed by mixed assemblages dominated by diatoms (DiTullio and Smith, 1996; Arrigo et al., 1999). This intense phytoplankton bloom results in a substantial seasonal drawdown of macronutrients and $\mathrm{CO}_{2}$ within the polynya (Gordon et al., 2000; Smith et al., 2006). With the Antarctic continental shelves being an important source of oceanic deep water formation (Orsi et al., 2002; Orsi and Wiederwohl, 2009), nutritional controls on primary productivity in the Ross Sea are an important influence on the Southern Ocean $\mathrm{CO}_{2}$ sink (Marinov et al., 2006; Arrigo et al., 2008).

There have been a number of trace metal-phytoplankton studies in the Ross Sea (Martin et al., 1990; Capodaglio et al., 1998; Fitzwater et al., 2000; Sedwick et al., 2000; Coale et al., 2005; Corami et al., 2005; Grotti et al., 2005; Bertrand et al., 2007). The Ross Sea Polynya exhibits nutrient-like depletion of dissolved iron to low concentrations $(\sim 0.1 \mathrm{nM})$ that has been shown to limit algal growth rates (Martin et al., 1990; Sedwick et al., 2000; Cochlan et al., 2002; Coale et al., 2003; Bertrand et al., 2007). Enhanced iron concentrations have been observed in proximity to melting sea ice and the sea floor, implicating these as important regional sources of dissolved iron (Sedwick and DiTullio, 1997; Fitzwater et al., 2000; Sedwick et al., 2000, 2011; Coale et al., 2005; Grotti et al., 2005). Zinc in the Ross Sea shows a seasonal drawdown, with a significant labile particulate fraction that allows recycling of $\mathrm{Zn}$ in the upper water column (Fitzwater et al., 2000; Coale et al., 2005). Two bottle incubation experiments in the Ross Sea have observed stimulatory zinc effects: in one instance a combined treatment of zinc and iron resulted in an increase of both chlorophyll and nitrate utilization relative to the iron-only treatment, suggestive of secondary zinc limitation within phytoplankton communities (Cochlan et al., 2002). In another experiment, a zinc-only addition caused an increase in chlorophyll relative to the control treatment (Coale et al., 2003), suggestive of independent colimitation (Saito et al., 2008).

Cobalt measurements were included in a previous geochemical study of the Ross Sea (Fitzwater et al., 2000), yet there was little discussion of its geochemistry in that study. We recently documented colimitation of phytoplankton growth by iron and the cobalt-containing vitamin $\mathrm{B}_{12}$ biomolecule in the Ross Sea during early austral summer 2005 (Bertrand et al., 2007), similar to reports of $B_{12}$ col- imitation of phytoplankton in other high latitude and coastal regions (Panzeca et al., 2006; Sañudo-Wilhelmy et al., 2006; Gobler et al., 2007). The mechanism for this colimitation in the Ross Sea appears to be related to the source of $B_{12}$ : the capacity for $\mathrm{B}_{12}$ biosynthesis is only present in some bacteria and archaea and is absent in all eukaryotic phytoplankton, while this vitamin is required by a majority of phytoplankton (Droop, 1974, 2007). The extent of the phytoplankton iron- $\mathrm{B}_{12}$ colimitation response was observed to be inversely related to bacterial abundances (Bertrand et al., 2007), consistent with the notion that the $\mathrm{B}_{12}$ biosynthesizing community is at times inadequate to supply iron replete phytoplankton in these experiments. The Ross Sea may be particularly prone to $\mathrm{B}_{12}$ colimitation due to the absence of $\mathrm{B}_{12^{-}}$ producing cyanobacterial populations in polar waters and the low heterotrophic bacterial abundances in the Ross Sea during austral spring (Ducklow et al., 2001), creating a temporal lag between $\mathrm{B}_{12}$ production and phytoplankton demand. Additions of inorganic cobalt did not stimulate growth in shipboard bioassay experiments (Bertrand et al., 2007), in contrast to other tropical regions where iron-cobalt colimitation (or secondary limitation) has been observed (Martin et al., 1989; Saito et al., 2005, 2008). In addition, cobalt has been suggested to limit $\mathrm{B}_{12}$ biosynthesis and community growth in sea ice phytoplankton and microbial communities in the southern Ross Sea (Gordon and Sullivan, 2008).

Recent studies have found that micronutrient drawdown can be an important process in controlling the distribution of Co in ocean surface waters (Ellwood and van den Berg, 2001; Saito and Moffett, 2002; Saito et al., 2004, 2005; Ellwood et al., 2005; Noble et al., 2008). This contrasts with earlier reviews that characterized Co as controlled by scavenging removal processes (Whitfield and Turner, 1987; Nozaki, 1997). Elements such as $\mathrm{Co}, \mathrm{Fe}, \mathrm{Cu}$, and (at high latitudes) $\mathrm{Mn}$ are considered hybrid-type metals, due to their oceanic distributions being strongly affected by both micronutrient uptake and scavenging processes (Bruland and Lohan, 2003; Noble et al., 2008). In addition, organic ligands have been shown to bind Co very strongly and are believed to provide an important control on Co biological availability as well as potentially protecting Co from scavenging in the ocean (Ellwood and van den Berg, 2001; Saito and Moffett, 2001; Saito et al., 2002, 2005, 2008; Ellwood et al., 2005). An experiment that compared Co enrichment incubations with and without the natural phytoplankton and microbial community demonstrated a biological origin of these cobalt ligands in the Costa Rica Dome region (Saito et al., 2005).

The water column biogeochemistry of cobalt has been shown to be connected to the biogeochemical cycles of $\mathrm{Zn}$, $\mathrm{Cd}$, and $\mathrm{Mn}$. While, as mentioned above, Co is required for the biomolecule $\mathrm{B}_{12}$, it is also one of three elements (with $\mathrm{Zn}$ and $\mathrm{Cd}$ ) that are capable of substituting in the active site of two important marine carbonic anhydrase metalloenzymes (the $\mathrm{Zn} / \mathrm{Co} \mathrm{DCA} 1$ and the $\mathrm{Cd} / \mathrm{Zn} \mathrm{CdCA} 1$ ), while maintaining enzymatic activity (Roberts et al., 1997; Lane et al., 2005). 
Such biochemical substitution, known as cambialism, appears to be an important adaptation to life in ocean surface waters where these micronutrients are often depleted (Saito et al., 2008). Physiological evidence of this Co-Zn substitution has been demonstrated in the Ross Sea phytoplankter Phaeocystis antarctica (Saito and Goepfert, 2008). In addition, low $p \mathrm{CO}_{2}$ is known to cause several fold increases in the $\mathrm{Cd}: \mathrm{P}$ ratio of particulate material in field experiments off the coast of California, likely due to upregulation of carbonic anhydrase enzymes (Lane and Morel, 2000; Cullen and Sherrell, 2005). Co geochemistry is also tied to that of Mn, where it has been shown that Co can be co-oxidized by manganeseoxidizing bacteria, and this is likely a critical pathway for the scavenging removal of Co from seawater (Tebo et al., 1984; Moffett and Ho, 1996).

Here we report measurements of total dissolved cobalt and cobalt speciation from two cruises in the Ross Sea, in austral spring of 2006 and austral summer of 2005. Together these data provide information on the seasonal influences of seaice retreat and phytoplankton succession on the distribution and cycling of cobalt in these Antarctic shelf waters. This first detailed examination of cobalt biogeochemistry in the Ross Sea serves as a companion study to our previous work on iron- $\mathrm{B}_{12}$ colimitation in this region (Bertrand et al., 2007).

\section{Materials and methods}

\subsection{Cruise track}

Samples were collected on two cruises aboard the icebreaker RVIB Nathaniel B. Palmer in the Ross Sea as part of the CORSACS program (Controls on Ross Sea Algal Community Structure; see www.whoi.edu/sites/corsacs). The first cruise (NBP0601, CORSACS-1) occurred in austral summer 2005-2006, sampling the Ross Sea from 27 December 2005 to 23 January 2006 (Fig. 1a); the second cruise (NBP0608, CORSACS-2) occurred in austral spring-early summer 2006, sampling the Ross Sea from 8 November 2006 to 3 December 2006 (Fig. 1b), as well as in the Southern Ocean en route to and returning from the Ross Sea (Fig. 1c). The southern transect of CORSACS-1 entered the Bay of Whales (Station NX9), a natural indentation in the Ross Ice Shelf created by Roosevelt Island, which was the southernmost point reached by any ship at the time of our expedition.

\subsection{Sampling methodologies}

Seawater samples for trace metals analysis were collected using either $5 \mathrm{~L}$ Teflon-coated external spring Niskin-X samplers (General Oceanics Inc., described as NX samples) or $2.5 \mathrm{~L}$ and $10 \mathrm{~L}$ Go-Flo samplers (General Oceanics Inc.). The Niskin-X and $10 \mathrm{~L} \mathrm{Go-Flo} \mathrm{bottles} \mathrm{were} \mathrm{deployed} \mathrm{on} \mathrm{a} \mathrm{non-}$ metallic line (Spectra) and closed using solid PVC messengers, whereas the $2.5 \mathrm{~L}$ Go-Flo samplers were mounted on an 11-position rosette unit modified for trace metal sampling, which was deployed on the Spectra line. The rosette unit was programmed to close the samplers at pre-determined times on the upcast, with the precise depth of sampler closure determined using an integrated pressure sensor. The NX vertical profiles typically consisted of samples obtained from 9 Niskin-X samplers and two additional $10 \mathrm{~L} \mathrm{Go-Flo}$ samplers; two vertical profiles (Station 54 and JR23) were obtained using only the Go-Flo samplers. Upon recovery, seawater samples were filtered through either $0.2 \mu \mathrm{m}$ Supor Acropak filter cartridges (Pall Corp., for NX samples) prerinsed with filtered surface seawater, or $0.4 \mu \mathrm{m} 144 \mathrm{~mm}$ polycarbonate membrane filters (GE, Osmonics, for Go-Flo samples) pre-cleaned with hydrochloric acid and Milli-Q deionized water. Cobalt was also measured in samples from three surface transects during CORSACS-1, collected using a trace-metal clean towed fish sampler deployed at $\sim 3 \mathrm{~m}$ depth while underway at $\sim 5$ knots, with samples filtered using in-line $0.2 \mu \mathrm{m}$ Supor Acropak filters (Bruland, 2005). All sample bottles were washed by soaking in $1 \%$ citranox overnight, rinsing thoroughly with Milli-Q, soaking in $10 \%$ Instra-analyzed $\mathrm{HCl}$ (Baker, Inc.) for two weeks, followed by thorough Milli-Q rinsing and soaking with dilute $(\mathrm{pH} 2)$ Instra-analyzed $\mathrm{HCl}$ overnight. Bottles were rinsed with seawater prior to filling, and samples were refrigerated in darkness until analysis.

\subsection{Total dissolved cobalt analyses}

Total dissolved cobalt (dCo), which is defined as total Co determined in filtered UV-irradiated seawater samples, was analyzed using a cathodic stripping voltammetry (CSV) protocol modified from our previous studies (Saito and Moffett, 2001, 2002; Saito et al., 2004, 2005), with the addition of an automated titration system and a slight decrease in reagent usage. Briefly, seawater samples were digested in quartz tubes for $1 \mathrm{~h}$ at ambient $\mathrm{pH}$ using a Metrohm UV digestor cooled with a Brinkmann water chiller. After this treatment, $9.25 \mathrm{~mL}$ of sample were pipetted into a Teflon sample cup that had been pre-rinsed with a small aliquot of sample; to this was added $50 \mu \mathrm{L}$ of $0.5 \mathrm{M} \mathrm{N}$-(2-hydroxyethyl)piperazine-N-(3propanesulfonic acid) buffer (EPPS, Sigma), $30 \mu \mathrm{L}$ of $0.1 \mathrm{M}$ dimethylglyoxime (DMG; Sigma-Aldrich), and $0.75 \mathrm{~mL}$ of $1.5 \mathrm{M}$ sodium nitrite (Fluka). These three reagents were purified as previously described (Saito and Moffett, 2001; Saito et al., 2004, 2005). Instrumentation consisted of two Metrohm 663 hanging mercury drop stands, each interfaced to an Eco-Chemie $\mu$ Autolab III, IME interface device, and portable Windows XP computer running GPES Electrochemical software (Eco-Chemie). Samples were purged for $3 \mathrm{~min}$ with filtered ultra high purity nitrogen gas at room temperature, and voltammetric scans were performed at stirrer speed 5 using the large drop size. The CSV analysis involved deposition for $180 \mathrm{~s}$ at $-0.6 \mathrm{~V}$ followed by a high speed scan from $-0.6 \mathrm{~V}$ to $-1.4 \mathrm{~V}$ at $10 \mathrm{~V} \mathrm{~s}^{-1}$. Total dissolved cobalt 

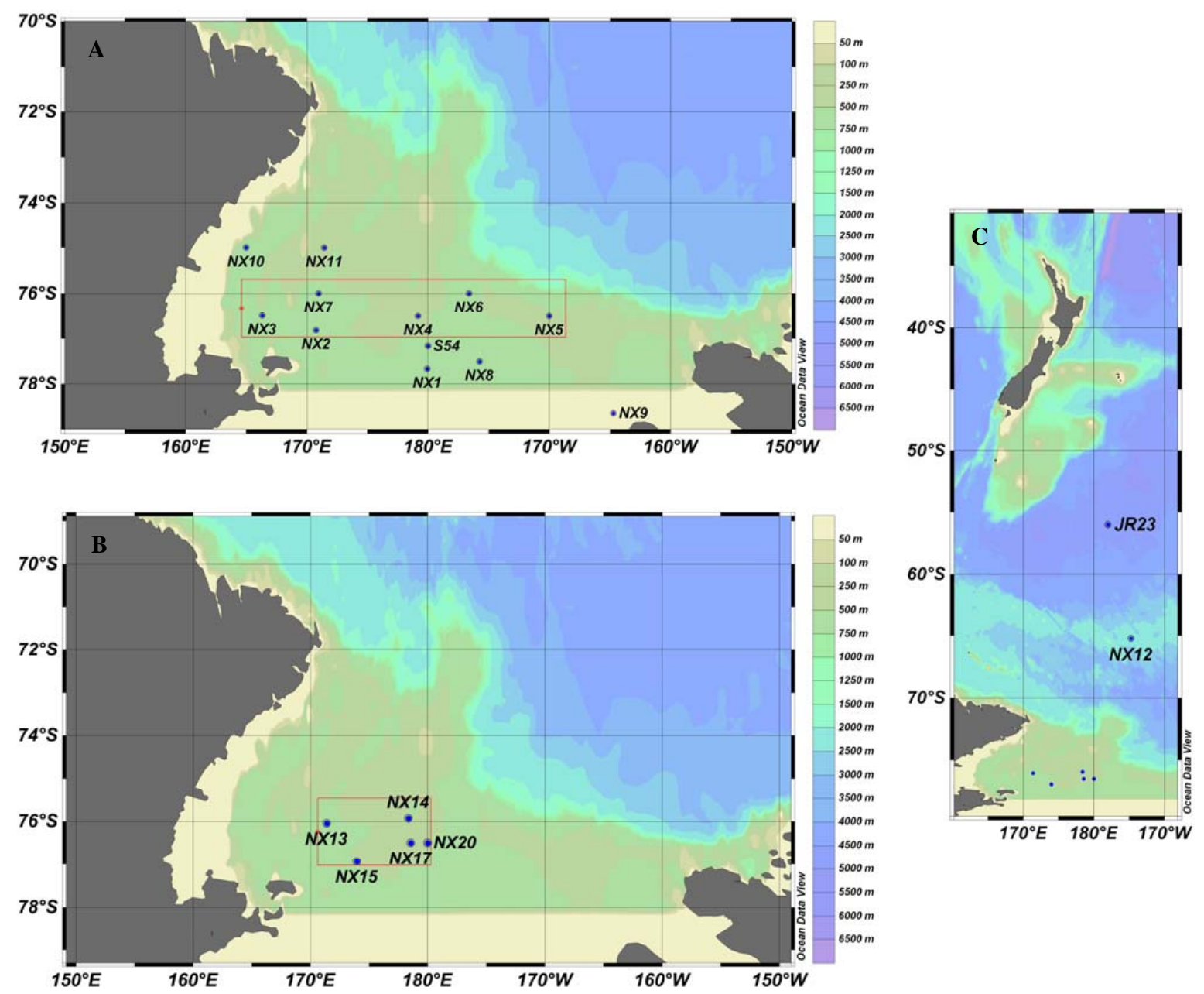

Fig. 1. Geographic locations of trace metal sampling sites in the Ross Sea of Antarctica and the Southern Ocean. (A) Locations of CORSACS1 stations NX1-11 sampled during the austral summer (27 December 2005-22 January 2006). (B) Locations of CORSACS-2 stations NX1320 sampled in the spring-early summer (16 November 2006-3 December 2006). (C) Locations of stations NX12 and JR23 in the Southern Ocean during CORSACS-2. The polynya was smaller during CORSACS-2 as shown by the smaller sampling area compared to CORSACS1. Station NX9 was in the Bay of Whales area, the southernmost point reached by any ship at the time. Areas enclosed in the red boxes are presented as vertical sections in Fig. 4.

was quantified by standard additions with a Metrohm Dosimat, using a $5 \times 10^{-9} \mathrm{M} \mathrm{CoCl}_{2}$ standard solution prepared from a 1000 ppm Co atomic absorption standard (Fisher Scientific). A GPES script was programmed for three replicate scans of the sample prior to adding Co, followed by a scan after each of four automated $25 \mathrm{pMCo}$ additions. Cobalt concentrations were calculated by dividing the mean of the triplicate sample scans by the standard addition slope determined by linear regression analysis, followed by reagent dilution and the following blank corrections for each set of reagents: $5.5 \pm 1.0 \mathrm{pM}$ for the CORSACS- 1 dCo profiles (sample set analyst M.A.S.), $13.4 \mathrm{pM}$ for the CORSACS-1 dCo surface transects and labile Co measurements (sample set analyst A.E.N.), and $8.3 \pm 1.3 \mathrm{pM}$ for the CORSACS-2 $\mathrm{dCo}$ and labile Co measurements, (sample set analyst T.J.G.) as determined by running blank seawater as previously de- scribed (Saito and Moffett, 2001). Triplicate analysis of a surface sample from the Ross Sea using this automated method yielded $27.8 \mathrm{pM} \pm 0.7 \mathrm{pM}$ (2.6\% RSD). Linear regressions of the standard additions data typically yielded $r^{2}$ values of 0.99 or greater, with samples being reanalyzed if $r^{2}<0.99$. Analyses were primarily conducted at sea, although some refrigerated samples from CORSACS-2 were analyzed in our shore-based laboratory within two months after the cruise. This analytical method is identical to that used for our submitted analyses of the intercalibration samples and vertical profile from the US GEOTRACES intercalibration program (Bruland et al., 2010), with the exception that these CORSACS samples were run "fresh" at ambient $\mathrm{pH}$, while GEOTRACES samples were acidified, stored, and neutralized prior to analysis. 


\subsection{Cobalt chemical speciation: labile cobalt}

The chemical speciation of dissolved cobalt was determined using a high-throughput labile Co method as previously described (Saito et al., 2004, 2005). Briefly this approach involves the analytical system described above for total dissolved cobalt, now with overnight equilibration $(>8 \mathrm{~h}$ ) of filtered seawater with $3 \times 10^{-4} \mathrm{MDMG}$ at room temperature, which allows for quantification of ligand within the detection window for $\mathrm{K}_{\mathrm{CoL}}$ of $10^{13.7}$ to $10^{15.7}$, calculated using an estimated $50 \mathrm{pM}$ natural organic cobalt ligand concentration and 10-fold range above and below a side reaction coefficient of $\alpha_{\text {CoHDMG2 }}$ of 28460 (Saito et al., 2005). Conditional stability constants are not calculated in this high-throughput method. After equilibration, EPPS and nitrite are added and the sample is titrated with a Co standard as described for the dCo determinations above, but without the UV-irradiation treatment. The result is an estimation of what we refer to as labile cobalt, which is the dissolved cobalt that is not bound by the natural strong organic ligands following equilibration.

\subsection{Cobalt uptake rates}

Addition of the radiotracer ${ }^{57} \mathrm{Co}$ to natural seawater samples was used to measure the rate of cobalt uptake by phytoplankton $(>2 \mu \mathrm{m})$ communities. ${ }^{57} \mathrm{CoCl}_{2}$ (Isotope Products Laboratories, Valencia, CA; 99\% radionuclide purity in $0.1 \mathrm{M} \mathrm{HCl}$ ) was diluted in $\mathrm{pH} 2$ Milli-Q water to $1.7 \mu \mathrm{Ci} \mathrm{mL}^{-1}(4.3 \mathrm{nM})$, and then again diluted to $\sim 0.1 \mathrm{nM}$ ${ }^{57} \mathrm{Co}$ in $0.4 \mu \mathrm{m}$-filtered seawater. An equilibrated seawater stock solution was prepared once for each cruise and used throughout for uniformity, allowing $24 \mathrm{~h}$ equilibration before the first rate measurements and storing at $4{ }^{\circ} \mathrm{C}$ in darkness between uses. For these measurements, 60 or $150 \mathrm{~mL}$ polycarbonate bottles were filled with unfiltered seawater collected in the trace-metal clean Niskin-X or Go-Flo bottles, deployed as described above. The polycarbonate bottles were initially cleaned as described above, and then re-used for additional measurements after successive rinses with $10 \% \mathrm{HCl}, \mathrm{pH} 2$ Milli-Q water, and seawater. Within half an hour of the seawater collection, approximately $0.5 \mathrm{pmol} \mathrm{L}^{-1}$ of ${ }^{57} \mathrm{CoCl}_{2}$ was added to each bottle, then bottles were placed in a deckboard incubator shaded to $\sim 20 \%$ ambient surface irradiance with neutral density screening material. Ambient temperature $\left(-1 \pm 1^{\circ} \mathrm{C}\right)$ was maintained by a constant flow of surface seawater through the incubators. After $24 \mathrm{~h}$, the incubations were filtered through $2 \mu \mathrm{m}$ polycarbonate filter membranes and rinsed with $1-2 \mathrm{~mL}$ of $0.4 \mu \mathrm{m}$-filtered seawater. The filter was centered in a a tight-lid Petri dish (Fisher Scientific) sealed with Parafilm.

The ${ }^{57}$ Co radioactivity on each filter was determined using a Canberra Germanium Gamma detector within 20 months of sample collection. Counts per minute at $122 \mathrm{keV}$ were corrected for decay and normalized to $\%$ uptake per day, calculated by dividing the activity on each filter by the total activ- ity added to each incubation bottle. Samples were counted long enough to achieve a counting error $<5 \%$. Cobalt concentrations were determined at each sampling depth for which a Co uptake rate measurement was made. Cobalt uptake rates were then calculated by multiplying the percent uptake per day by the total dissolved cobalt concentration. Control studies were conducted by killing the biological community with gluteraldehyde (1\% final concentration; Co added $3 \mathrm{~h}$ after gluteraldehyde added) or heat $(180 \mathrm{~mL}$ sample microwave heated for $3 \times 5 \mathrm{~min}$; Co added $3 \mathrm{~h}$ after heat killed). Killed control treatments were filtered after $24 \mathrm{~h}$ incubation at $0^{\circ} \mathrm{C}$ in the dark.

\subsection{Pigment and nutrient analyses}

Phytoplankton pigment samples (0.5-2L) were filtered (Whatman GF/F filters), flash frozen in liquid nitrogen, and stored at $-80^{\circ} \mathrm{C}$ prior to analysis by HPLC as previously described (DiTullio and Geesey, 2002), with a slight modification using the Zapata method (Zapata et al., 2000). Water column samples for pigments were collected using a standard CTD rosette system at the same locations as trace-metal water sample collections. Filtered samples for macronutrients were taken from the Niskin-X and Go-Flo trace metal samplers and analyzed at sea using an autoanalyzer method modified from standard WOCE protocols (Gordon et al., 1993).

\subsection{Data analysis and repository}

Dissolved ecological stoichiometries were obtained from the slope of linear regressions. One-way and two-way least squares regressions were used for the vertical profile $\mathrm{dCo}$ dataset, with the former assuming one dependent and one independent variable, and the latter assuming two dependent variables and performed in MATLAB using the script lsqfitma.m. Previous studies used here for comparisons used one-way linear regressions, but the differences between slopes are small relative to the environmental variability discussed. The cobalt and nutrient data presented in this manuscript (a total of $463 \mathrm{dCo}$ and labile cobalt values) have been deposited into the US Biological and Chemical Oceanography Data Management Office database under the CORSACS program (BCO-DMO http://bcodmo.org/).

\section{Results and discussion}

The Ross Sea of Antarctica serves as an ideal end member in the study of the marine biogeochemistry of cobalt. With its extreme low temperatures, seasonal sea ice cover, high biological productivity, and low atmospheric dust inputs, this sea presents an environment quite distinct from other oceanic regimes where Co has been studied. Here we consider total dissolved and cobalt speciation data from cruises in austral summer 2005 and austral spring 2006 that together provide a seasonal perspective on the distribution of this micronutrient 

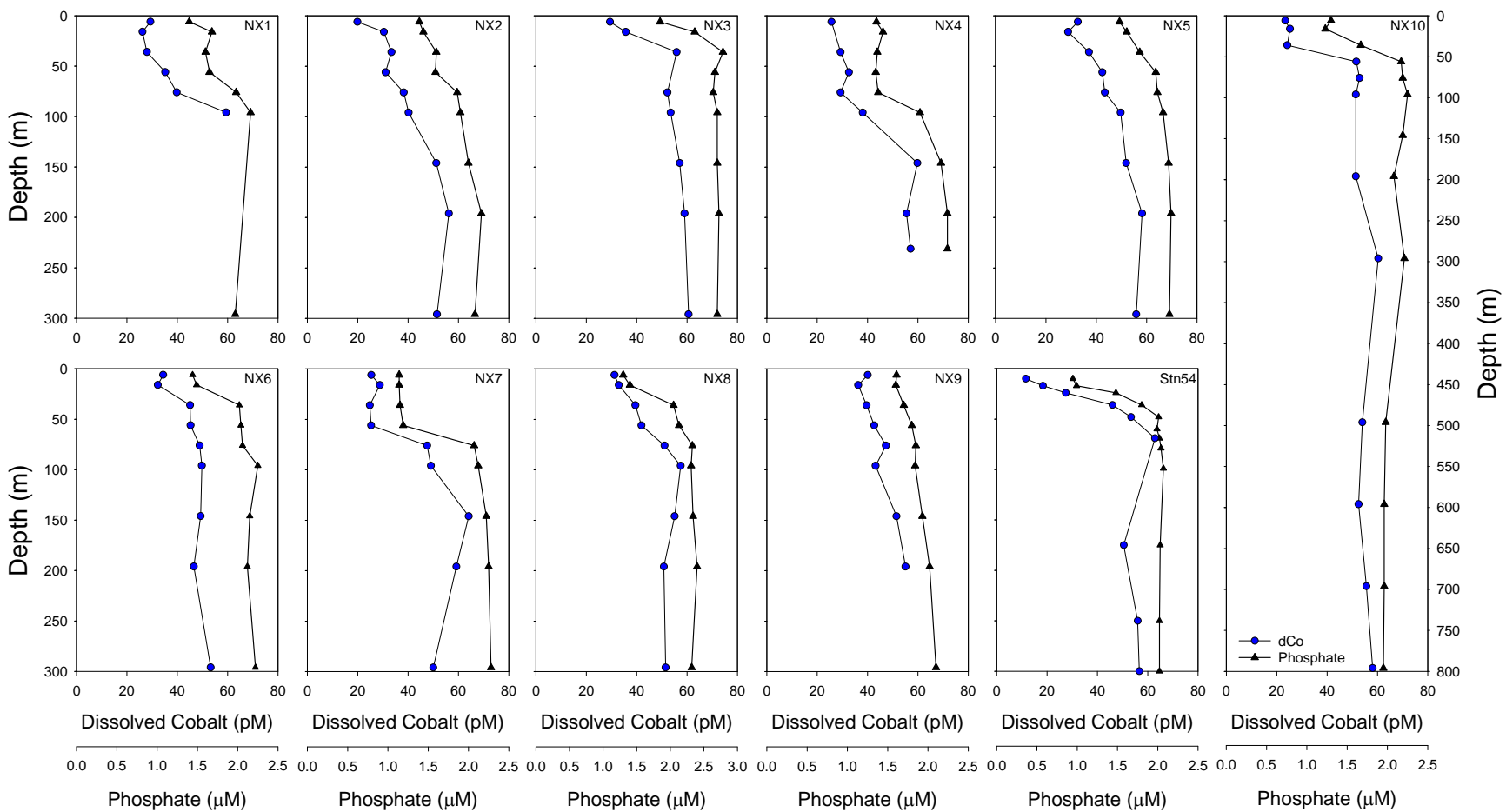

Fig. 2. Vertical profiles of total dissolved cobalt (dCo, circles) and soluble reactive phosphate (triangles) from austral summer in the Ross Sea (CORSACS-1). Note the similarity in vertical structure for both nutrients throughout the water column.

element. The Ross Sea Polynya was almost completely open during the summer 2005-2006 cruise, but was only in the early stages of formation during the spring 2006 cruise, as revealed by the geographic distribution of stations occupied during the cruises (Fig. 1a, b) and estimated sea ice coverage shown by Sedwick et al. (2011). In this study we observed four salient features with regard to the geochemistry of cobalt: (1) nutrient-like vertical profiles, (2) correlations between cobalt and soluble reactive phosphorus, (3) no evidence of scavenging removal in intermediate waters, and (4) non-saturating concentrations of strong cobalt-binding ligands resulting in the presence of significant concentrations of labile cobalt.

\subsection{Dissolved cobalt: vertical profiles and surface transects}

Total dissolved cobalt profiles from 11 stations in austral summer 2005-2006 (CORSACS-1 cruise) and 7 stations in austral spring 2006 (CORSACS-2 cruise) are presented in Figs. 2 and 3. All profiles from the summer cruise (Fig. 2) reveal surface depletion that likely reflects biological uptake and export. The Bay of Whales station NX9 showed the least surface depletion, likely due to lower productivity and recent retreat of sea-ice cover. Surface depletion was also evident in most profiles from the austral spring cruise (Fig. 3), but to a lesser extent than observed in the preceding summer. Almost all dCo profiles showed strong similarity in verti- cal structure to soluble reactive phosphate, consistent with biological uptake and vertical export of $\mathrm{dCo}$ due to phytoplankton. The dCo profiles from each cruise were used to create quasi-zonal sections that clearly reveal the surface depletion of dCo across the Ross Sea region (Fig. 4, top panels). The phytoplankton assemblage present when $\mathrm{dCo}$ and $\mathrm{PO}_{4}^{3-}$ were both drawn down included Phaeocystis antarctica and diatoms, as determined by pigment analyses (Fig. 4, bottom panels). The vertical sections in Fig. 4 do not suggest any obvious sources of dissolved cobalt to the water column, such as atmospheric, sedimentary or meltwater inputs. This is in contrast to iron where sedimentary sources appear to be present over Ross Bank (NX17 and NX20) manifested as increased dissolved iron at 250-300 m depth (Sedwick et al., 2011). In addition meltwater sources of iron appeared to be present in the water column from these cruises (Sedwick et al., 2011). These comparative results are perhaps not particularly surprising since atmospheric deposition tends to produce surface maxima in dCo primarily in regions of high dust deposition, such as the western Philippine Sea (Wong et al., 1995; Saito and Moffett, 2002). Large plumes of dissolved Co appear in oceanic oxygen minimum zones, likely due to a combination of escape of Co from sediments exposed to low bottom water oxygen as well as stabilization of Co in the low oxygen water column (Heggie and Lewis, 1984; Saito et al., 2004, 2005). Since the Ross Sea is a relatively well oxygenated region, these processes may not 

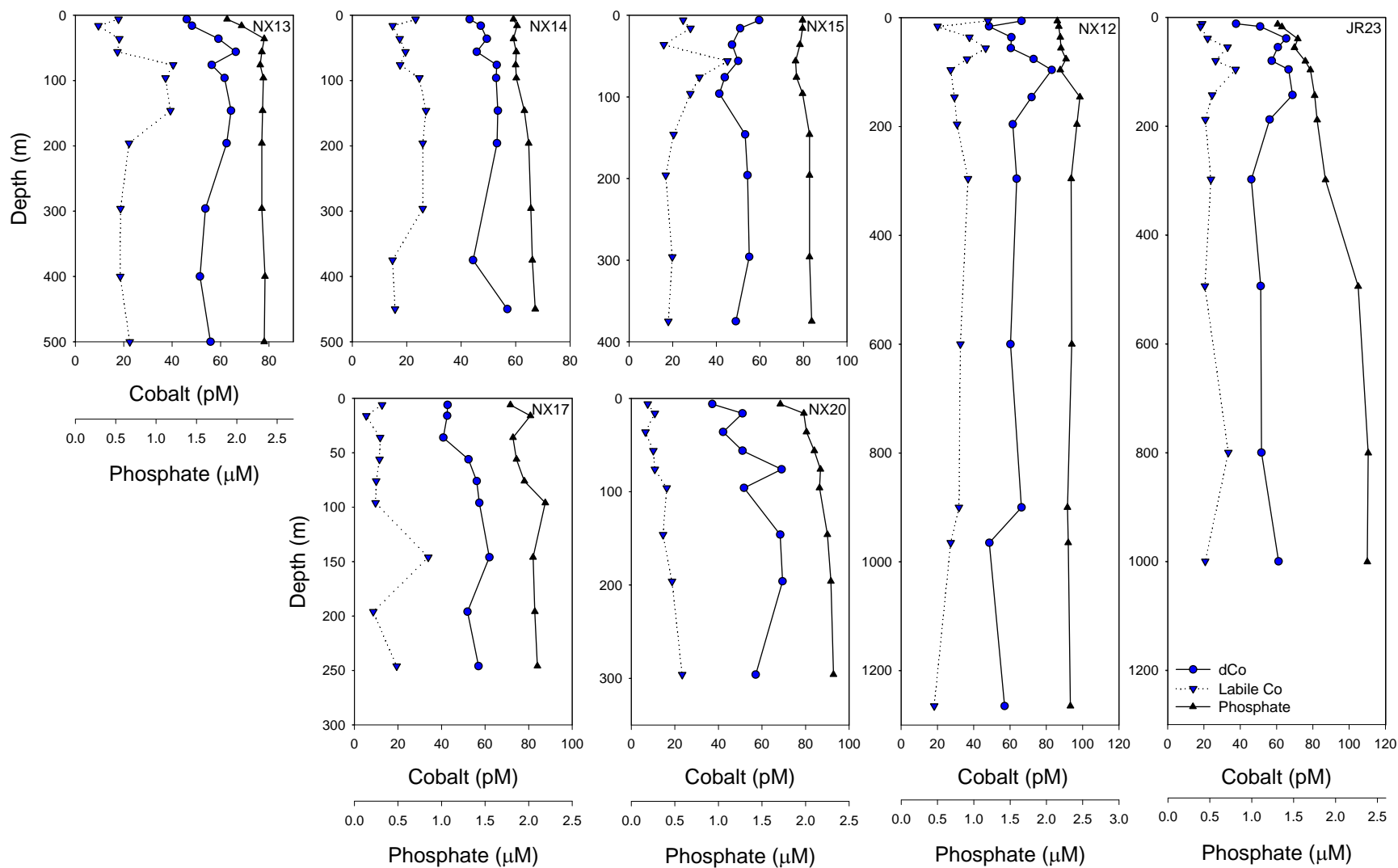

Fig. 3. Vertical profiles of total dissolved cobalt (dCo, circles), labile cobalt (downward triangles, dashed line) and soluble reactive phosphate (upward triangles, solid line) from late spring/early summer in the Ross Sea (CORSACS-2). The abundance of both nutrients is higher than in late summer. Southern Ocean stations NX12 and JR23 showed the effects of scavenging of cobalt below the euphotic zone.

be as important here. However, our sampling strategy did not include samples in close proximity to the sea floor that might reveal concentration anomalies associated with small input fluxes. Also, given the low Co:Fe ratio $(\sim 1: 2600)$ of crustal material (Taylor and McLennan, 1985), the accumulation and release of terrigenous material from sea ice would likely have a more subtle effect on the distribution of cobalt relative to iron, depending on relative solubilities of these two elements in lithogenic particles (Sedwick et al., 2007; Thuróczy et al., 2010).

Four surface-water transects of cobalt from the austral summer cruise were obtained using the underway towed fish. Trends in surface dCo ( $\sim 3 \mathrm{~m}$ depth) were broadly similar to the macronutrients, as shown in Fig. 5. In transect 2, for example, dCo concentrations varied between 17 and $59 \mathrm{pM}$, but were typically between $20-40 \mathrm{pM}$, with an average of $33 \pm 7.2 \mathrm{pM}$. The very western edge of the transect was near the seasonal ice edge, and showed lower salinity, nutrients, and $\mathrm{dCo}$, particularly along $76^{\circ} \mathrm{S}$ and $76.5^{\circ} \mathrm{S}$. The western portion of the surface transects also coincided with elevated primary productivity, particularly along the $75^{\circ} \mathrm{S}$ transect near Terra Nova Bay. Station NX10 within this bay was observed to have characteristics of High Salinity Shelf Wa- ter (HSSW) below $300 \mathrm{~m}$ (Corami et al., 2005; hydrographic data not shown), and although having elevated iron concentrations (0.5-0.7 nM; Sedwick et al., 2011), did not show elevated cobalt relative to the rest of our Ross Sea stations ( 65 pM; Fig. 2).

\subsection{Evidence for micronutrient behavior: correlation of cobalt with phosphate}

The similarities in the vertical and horizontal distributions of cobalt and phosphate were statistically significant based on a two-way linear regression of 164 vertical profile samples from CORSACS-1 and 2 (Table 1 and Fig. 6a, both seasons together $r^{2}=0.87$; CORSACS- 1 data only $r^{2}=$ 0.88 ). This analysis revealed a strong seasonal signal, with most of the spring cruise samples having total dissolved cobalt values greater than $\sim 45 \mathrm{pM}$ and phosphate greater than $\sim 1.75 \mu \mathrm{M}$, while for the summer cruise samples cobalt and phosphate concentrations either overlapped with those of the spring, or were depleted well below the spring concentrations due to biological activity and export from the euphotic zone (Fig. 6a). The surface transect samples from the summer cruise fall at the low end of the seasonal variability 

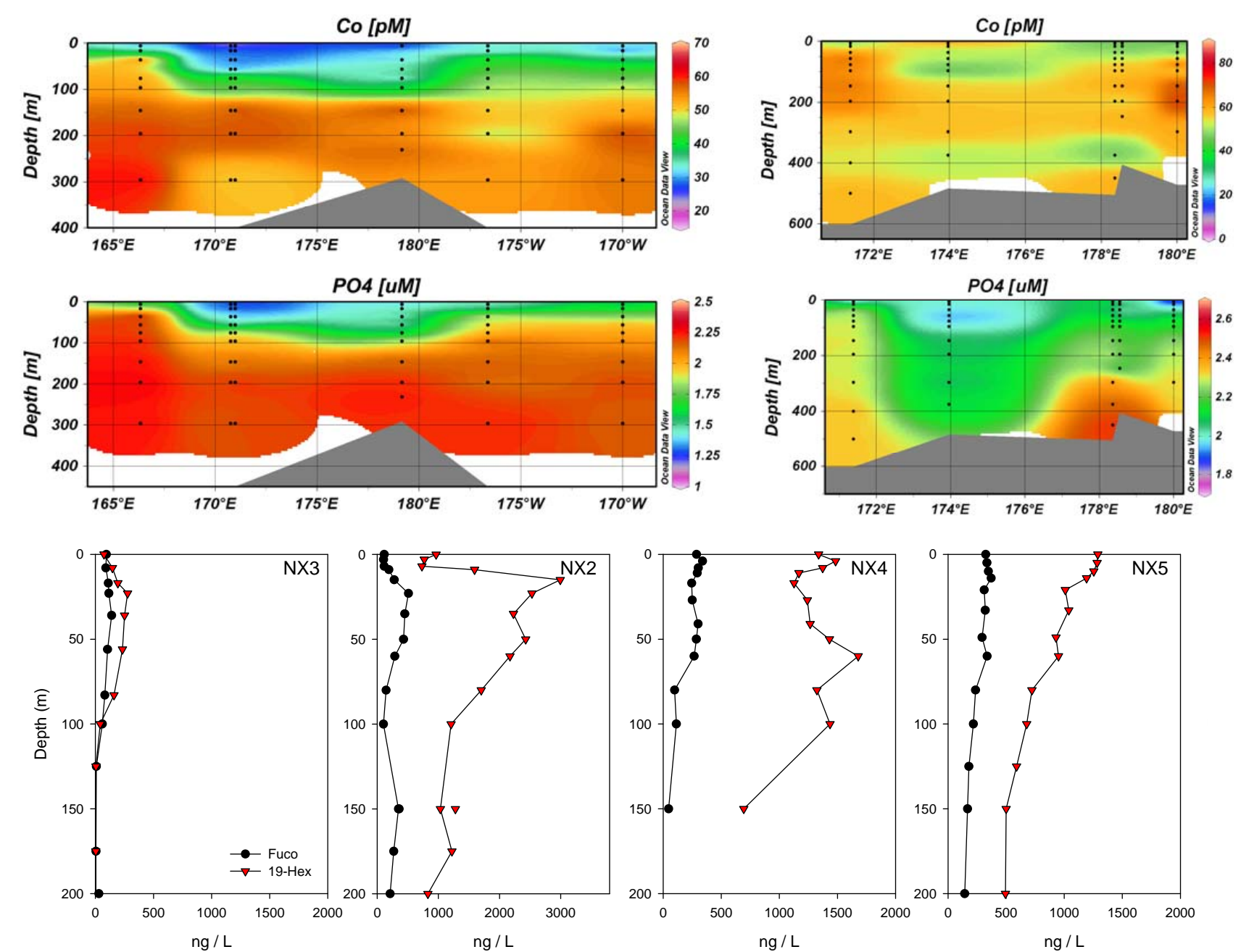

Fig. 4. Zonal sections of total dissolved cobalt and phosphate during summer (CORSACS-1; top left panel) and spring/early summer (CORSACS-2; top right panels). Stations enclosed within the red line in Fig. 1a and b are included in the zonal sections. Summer shows the cumulative effects of cobalt and phosphate removal by phytoplankton uptake and export. Representative vertical phytoplankton pigment distributions during the summer CORSACS-1 cruise across the section showed large haptophytes populations (19-Hexanolyoxyfucoxanthin, primarily Phaeocystis antarctica) and smaller diatom populations (Fucoxanthin) within the center of the region of nutrient drawdown.

$\left(\sim 30 \mathrm{pMdCo}, \sim 1.5 \mu \mathrm{M} \mathrm{PO} \mathrm{PO}_{4}^{3-}\right.$, Fig. $\left.6 \mathrm{~b}\right)$, with a thread of data plateauing at $\sim 20 \mathrm{pM} \mathrm{dCo}$ while phosphate continues to be depleted to $\sim 0.1 \mu \mathrm{M}$, perhaps due to a residual amount of complexed cobalt with low resultant bioavailability. A number of samples from surface transects yield data that lie off the linear dCo vs. $\mathrm{PO}_{4}^{3-}$ trend, suggesting an external input such as melting sea ice. Input from sea ice melt might be expected to cause deviations from the linear $\mathrm{dCo}: \mathrm{PO}_{4}^{3-}$ relationship, since accumulated lithogenic aeolian material should have an elevated Co:P ratio relative to biogenic matter. In addition, seawater metal: $\mathrm{PO}_{4}^{3-}$ relationships $\left(\mathrm{Cd}: \mathrm{PO}_{4}^{3-}\right.$ in particular) do not appear to be preserved within sea ice (Hendry et al., 2009), and sea ice can be quite depleted in phosphorus (McMinn et al., 1999). In general, deviation from the seawater metal:P relationship is expected to result from processes other than biological up- take and remineralization, such as aeolian deposition, particle scavenging, and oxidation/precipitation by Mn-oxidizing bacteria (Tebo et al., 1984), which should produce vectors in metal:phosphate space that are vertical rather than diagonal, as indicated in Fig. 7 (Noble et al., 2008). This type of vector analysis in $\mathrm{Co}: \mathrm{PO}_{4}^{3-}$ space appears to be useful in identifying sporadic and/or subtle influences by their deviation from the coherent uptake and remineralization signal within large datasets such as this. In contrast to this micronutrient behavior for $\mathrm{dCo}$ in the Ross Sea, the vertical structure of $\mathrm{dCo}$ at two Southern Ocean stations NX12 and JR23 (Fig. 1, right panel) showed increasing deviation from the observed Ross Sea phosphate relationship moving northward, where NX12 showed increased Co relative to $\mathrm{PO}_{4}^{3-}$ at $\sim 100 \mathrm{~m}$ and JR23 showed little coherence with phosphate (Figs. 3 and 6b). 

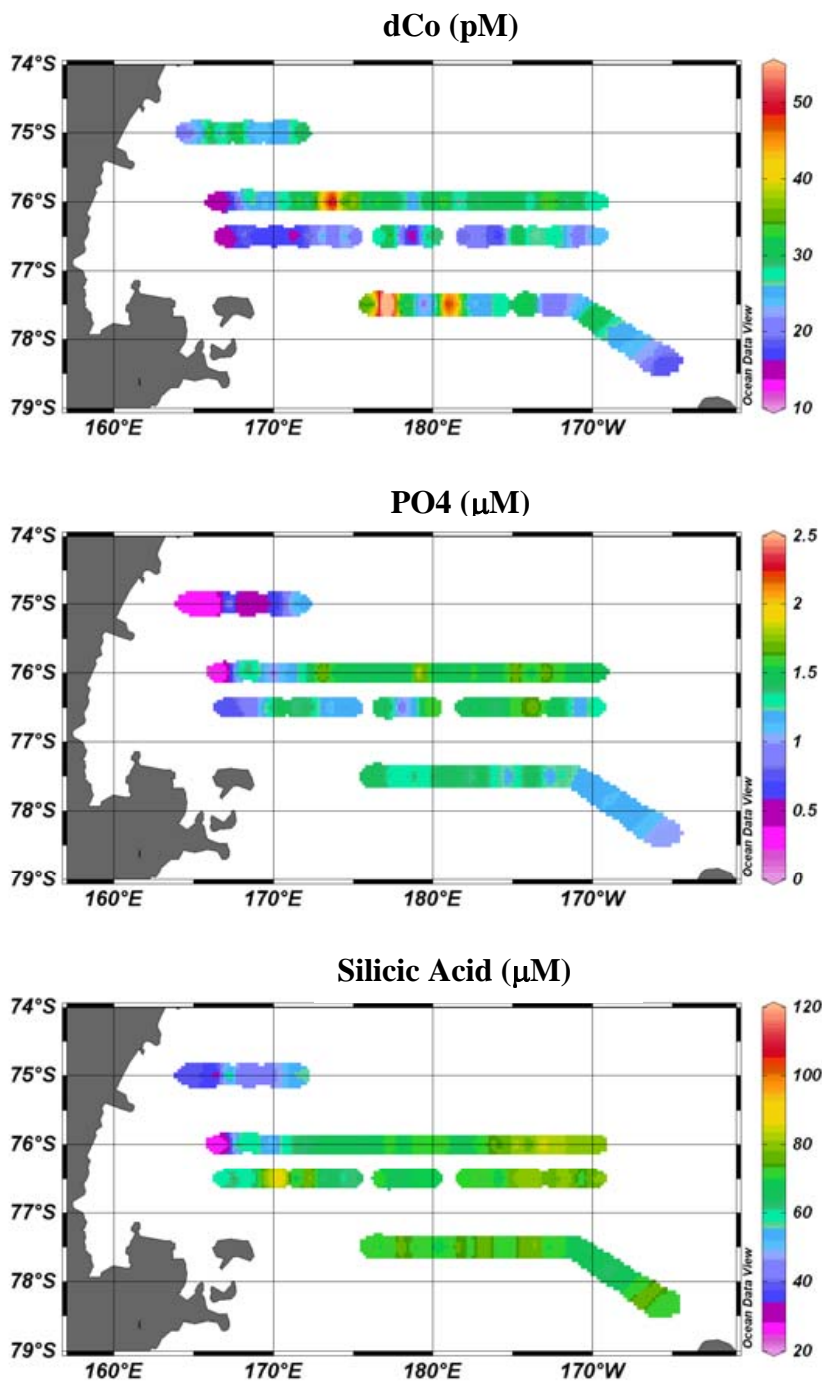

Fig. 5. Surface transects for total dissolved Co (dCo, top), soluble reactive phosphate (middle) and silicic acid (bottom) from CORSACS-1 1-22 January 2006. Total dissolved cobalt showed a general similarity to macronutrients throughout the transect. The very western edge of the transect was near the ice edge and showed a decrease in salinity, nutrients, and cobalt, particularly along $76^{\circ} \mathrm{S}$ and $76.5^{\circ} \mathrm{S}$. The western portion of the transects also had high primary productivity, particularly along the western edge of the $75^{\circ} \mathrm{S}$ transect near Terra Nova Bay.

\subsection{Chemical speciation of cobalt}

Cobalt speciation measurements revealed that while strong cobalt-binding ligands were present in all of the samples, a significant fraction of the total dissolved cobalt was not complexed by these ligands (Figs. 3 and 6c). We have previously described this unbound fraction as "labile" cobalt, with the assumption that it is bound by inorganic ligands or weak organic ligands (Saito et al., 2005, 2004). Comparison of total dissolved Co and labile Co in the Ross Sea shows that la- bile Co was usually detectable in significant concentrations (Fig. 6d). These cobalt-binding ligands were strong enough to be measured within our conditional stability constant detection window of $10^{13.7}$ to $10^{15.7}$, with experiments suggesting that the ligand strength exceeded our detection window ( $\mathrm{K}_{\text {cond }} \geq 10^{15.7}$, data not shown), as we have observed elsewhere (Saito et al., 2005). This abundance of labile cobalt is likely important in providing a bioavailable form of Co to eukaryotic phytoplankton (Saito et al., 2002, 2004). Moreover, the presence of measurable labile cobalt throughout the water column of the Ross Sea contrasts with observations in tropical and subtropical regions, where cobalt is often completely bound by strong ligands in the upper euphotic zone (Saito and Moffett, 2001; Saito et al., 2004, 2005; Noble et al., 2008). Exceptions to this appear to be related to significant sources of cobalt, such as in the Peru Upwelling Region, where a large flux of cobalt is thought to enter the system as labile cobalt, and where large phytoplankton community shifts occurred concurrently with changes in cobalt speciation (Saito et al., 2004).

It seems likely that cobalt-binding ligands are produced as a by-product of vitamin $\mathrm{B}_{12}$ biosynthesis and perhaps subsequent photochemical alteration. By this logic, the presence of microbes capable of producing the cobalt-containing vitamin $\mathrm{B}_{12}$ should be important to the generation of cobalt-binding ligands. Of the microbes potentially present in seawater, all publicly available marine cyanobacteria with genomes sequenced thus far appear to have components of the biosynthetic pathway (30 genomes as of July 2010, including Crocosphaera, Trichodesmium, Synechococcus, Prochlorococcus, and UCYN-A; M. A. Saito, personal observation, 2010, http://img.jgi.doe.gov/; Rodionov et al., 2003), while only some heterotrophic bacteria (SAR11 cannot) and no eukaryotic phytoplankton are capable of making $\mathrm{B}_{12}$ (Croft et al., 2005; Giovannoni et al., 2005; Bertrand et al., 2007). Moreover, none of the Antarctic heterotrophic bacteria with genomes currently sequenced contain the $\mathrm{B}_{12}$ biosynthetic pathway (Bertrand et al., 2011). In the Ross Sea, the marine cyanobacteria are numerically non-existent based on microscopy and pigment analysis (Caron et al., 2000; DiTullio, 2003; Bertrand et al., 2007), whereas they comprise a significant component of the microbial community in tropical and subtropical environments (Campbell et al., 1994; DiTullio et al., 2003). In addition, the heterotrophic bacterial community is known to be less numerous and exhibit a strong seasonal cycle in the Ross Sea, in contrast to temperate and tropical oceans (Ducklow et al., 2001). Amplification of the $c b i A$ cobalamin biosynthesis gene from DNA purified from the Ross Sea microbial community and the detection of the associated protein via mass spectrometry reveals an active population of heterotrophic bacteria capable of $B_{12}$ biosynthesis (Bertrand et al., 2011). The relationship between $\mathrm{B}_{12}$ and these cobalt-binding ligands is still uncertain, although we have observed that each has distinctly different chemical properties (M. A. Saito, personal observation, 
Table 1. Relationship between cobalt and phosphate in the Ross Sea and elsewhere.

\begin{tabular}{lllll}
\hline Geographic Location & $\begin{array}{l}\text { Depth range } \\
(\mathrm{m})\end{array}$ & $\mathrm{Co}(\mathrm{pM})$ & $\begin{array}{l}\Delta \mathrm{Co}: \Delta \mathrm{P} \\
\mu \mathrm{mol} \mathrm{mol}\end{array}$ & $r^{2}$ \\
\hline Ross Sea, Antarctica (this study) & $5-500$ & $19-71$ & 37.6 & 0.87 \\
NE Pacific (Martin et al., 1989) & $50-150$ & $7.9-32$ & 39.8 & 0.98 \\
NE Pacific (Martin et al., 1989) & $50-150$ & $28-40$ & 35.5 & 0.99 \\
NE Pacific (Martin et al., 1989) & $8-50$ & $25-55$ & 38.4 & 0.97 \\
Peru Upwelling Region (Saito et al., 2004) & 8 & $21-315$ & 248 & 0.83 \\
Equatorial Atlantic (Saito and Moffett, 2002) & 5 & $5-87$ & 560 & 0.63 \\
\hline
\end{tabular}
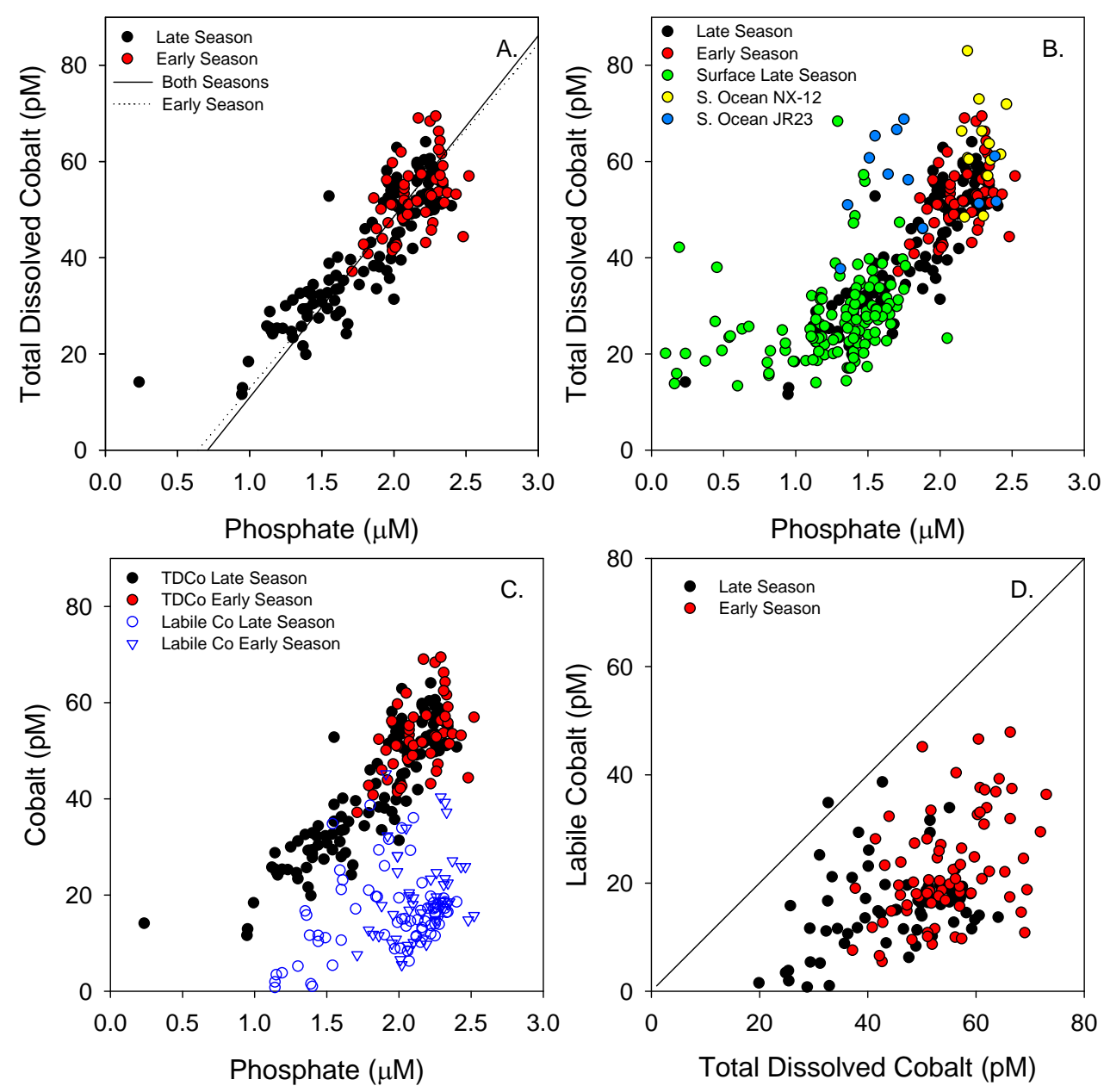

Fig. 6. (A) Total dissolved cobalt and phosphate were correlated throughout the water column of the Ross Sea. Both were noticeably higher in the spring (Early Season) than summer (Late Season), indicative of phytoplankton utilization and export. Linear regressions are shown for vertical profile datasets of both seasons (solid) and only CORSACS-1 (dashed). (B) Surface transects in the summer also showed a relationship between Co and phosphate, overlapping with and extending lower than the summer profile samples. Southern Ocean profiles NX12 and particularly JR23 showed less coherence with phosphate. (C) Labile cobalt from both spring and summer showed significant amounts of cobalt present as labile cobalt in the water column. (D) Labile cobalt from vertical profiles of CORSACS-1 and 2 versus total dissolved cobalt, with 1:1 line shown, shows how dCo is not saturated by cobalt binding ligands. 


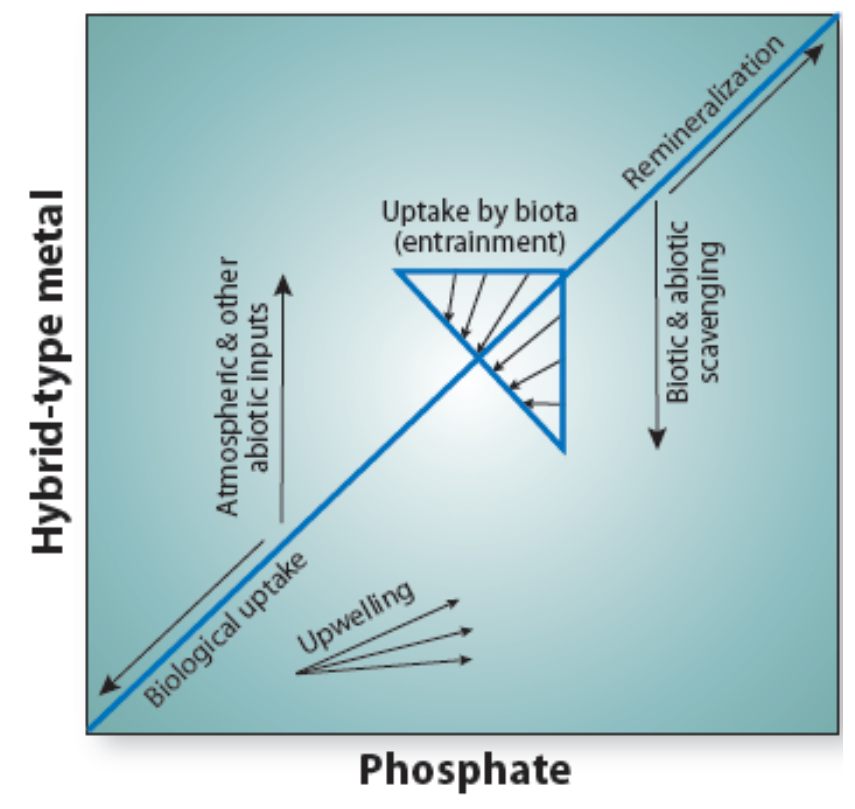

Fig. 7. A schematic showing vectors for processes influencing hybrid-type metals relative to phosphate, where hybrid-type metals refers to those that have the combination of micronutrient uptake and scavenging processes influencing vertical structure. Biologically influenced processes such as phytoplankton uptake and remineralization of particles create diagonal vectors (variable individual species metal quotas are aggregated for a community quota). Abiotic processes (or non-nutritive processes in the case of microbial manganese oxidation) such as aeolian deposition and scavenging result in near vertical vectors (Fig. 9d). Upwelling should result in a diagonal vector with a lower slope than the biotic vectors due to the effect of scavenging on removal of hybrid-type metal relative to phosphate. After Noble et al. (2008).

2010), suggesting they are not identical, but rather are linked via chemical transformation. If cobalt ligands are indeed a degradation product of vitamin $\mathrm{B}_{12}$, we hypothesize that the lack of cyanobacteria and low abundance of heterotrophic bacteria in the Ross Sea in the austral spring results in a low production rate of vitamin $\mathrm{B}_{12}$ and perhaps a commensurate low cobalt ligand production rate in the Ross Sea relative to temperate and tropical oceans. As mentioned above, we and others have observed phytoplankton colimitation by iron and vitamin $\mathrm{B}_{12}$ in the Ross Sea, Southern Ocean, and coastal environments (Panzeca et al., 2006; Sañudo-Wilhelmy et al., 2006; Bertrand et al., 2007; Gobler et al., 2007). Yet the heterotrophic bacteria cell numbers do increase by the end of austral summer in the Ross Sea (Ducklow et al., 2001; Bertrand et al., 2007): the presence of labile cobalt in the Ross Sea water column suggests that either the population of microbes present does not have comparable $\mathrm{B}_{12}$ production rates relative to the high summer phytoplankton $B_{12}$ demand, and/or that the Ross Sea microbial community is not being lysed and grazed as rapidly as in low-latitude microbial loop environments to allow the saturation of cobalt by ligands that we observe in regions such as the Costa Rica Dome and Sargasso Sea (Saito and Moffett, 2001; Saito et al., 2005). Thus, the distinctiveness of the polar bacterial community of the Ross Sea provides a likely explanation for both the lack of saturating concentrations of cobalt-binding ligands and the colimitation of phytoplankton growth by vi$\operatorname{tamin} B_{12}$ in these waters.

We have previously reported a biological origin for cobalt-binding ligands, through field experiments with a cyanobacterially-dominated microbial community (with marine Synechococcus cellular abundances $>10^{6}$ cells $\mathrm{mL}^{-1}$ ) in the Costa Rica Dome region of the Eastern Tropical North Pacific (ETNP). In that study, control treatments where the microbial population was removed by filtration did not show production of cobalt-binding ligands (Saito et al., 2005). Recently, Ellwood et al. (2005) have argued that the presence of increased abundances of cobalt-binding ligands south of the South Atlantic sector of the Antarctic Polar Front (APF), compared to a station north of the APF, contradicts our assertion that cyanobacteria contribute to the production of cobaltbinding ligands since Synechococcus populations largely disappear south of the APF. The results of the present study may reconcile our previous results from the ETNP and elsewhere with the data reported by Ellwood et al. (2005) based on three lines of reasoning. First, in our previous study we were careful to argue that the cyanobacterially-dominated microbial community was a source of ligands rather than solely the Synechococcus population since that field experiment could not differentiate the microbial source. Second, if the cobalt-containing vitamin $\mathrm{B}_{12}$ molecule is the source of cobalt-binding ligands, then populations of bacteria or archaea capable of biosynthesizing $\mathrm{B}_{12}$ are required to produce cobalt-binding ligands. The Costa Rica Dome and the Ross Sea then represent opposite extremes: very high cyanobacteria and heterotrophic cell abundances in the former, and no measurable cyanobacteria population and seasonally varying heterotrophic bacteria abundances in the latter, as described above (Ducklow et al., 2001; Saito et al., 2005). Ellwood et al.'s (2005) observation of a higher abundance of cobaltbinding ligands south of the APF relative to north of the APF could reflect increased heterotrophic bacterial abundances that accompany the three-fold increase in primary productivity they observed between their southern and northern APF sites. Third, in this study we measured cobalt speciation at two oceanic stations in the Southern Ocean (NX12 and JR23; Figs. 1 and 3$)$ that showed labile cobalt $(\sim 20$ pM) throughout the water column, similar to our findings in the Ross Sea. Together these observations are consistent with the notion of a relationship between $B_{12}$ biosynthesizing bacterial populations and cobalt-binding ligands: in the Ross Sea and our two oceanic Southern Ocean stations, cobalt-binding ligands are observed (Fig. 3), yet the cobalt ligands do not exist in saturating concentrations, resulting in much greater bioavailability of Co than is observed in tropical and subtropical regions (Saito et al., 2005). The highly productive interfacial waters 

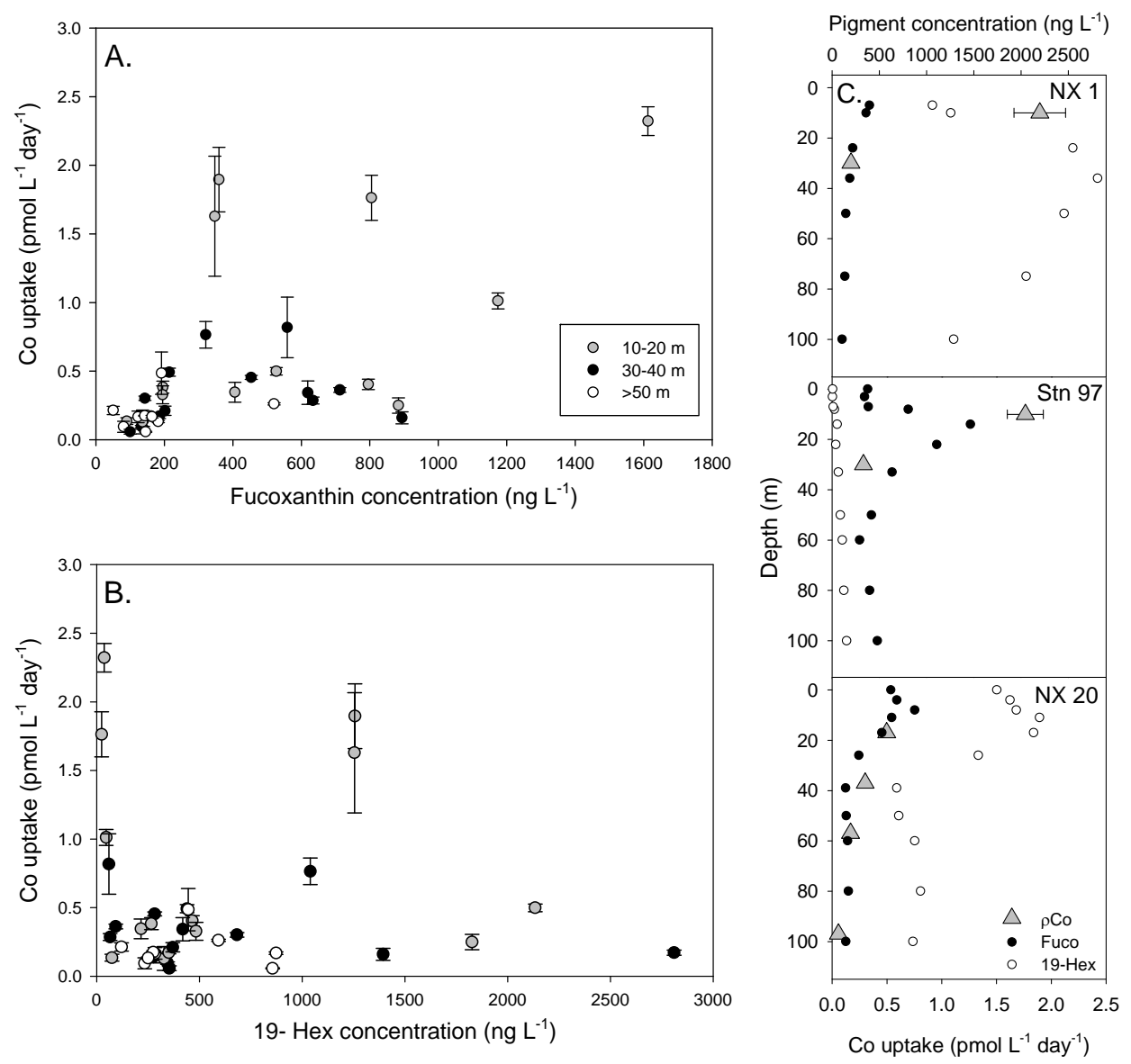

Fig. 8. Cobalt uptake rates and phytoplankton pigment concentrations from CORSACS-1 and 2. (A) Means of triplicate cobalt uptake rate measurements at three depth intervals (error bars are one standard deviation) versus the diatom indicator pigment fucoxanthin (Fuco) from the nearest depth. (B) Cobalt uptake versus the haptophyte indicator pigment 19-hexanolyoxyfucoxanthin (19-Hex). (C) Three representative profiles of Co uptake rates, Fuco and 19-Hex concentrations from NX1 and station 97 from CORSACS-1 and NX20 from CORSACS-2. Cobalt uptake rates show weak correlation with fucoxanthin $\left(\mathbf{A}, r^{2}=0.35\right)$ and no correlation with $19-$ Hex $\left(\mathbf{B}, r^{2}=0.003\right)$; although some high cobalt uptake rates co-occur with high 19-Hex abundance (C, NX1).

near the APF would then represent a situation intermediate between the Ross Sea and the tropics.

\subsection{Cobalt uptake rates}

Measurements of cobalt uptake from the dissolved phase to the $>2 \mu \mathrm{m}$ size fraction particulate phase approached $2.5 \mathrm{pmol} \mathrm{L}^{-1}$ day $^{-1}$ (Table 3, Fig. 8). Glutaraldehyde-killed control treatments showed little abiotic uptake $(\sim 2-4 \%$ of live uptake, Table 3). The observed biological uptake could be due to assimilation into cellular material and/or biologically-mediated co-oxidation with manganese into oxide minerals (Moffett and Ho, 1996). However, given the apparent lack of scavenging removal of dissolved Co from the mesopelagic zone (see Sect. 3.6) and low Mn euphotic zone abundances (Sedwick et al., 2000), it seems likely that biological oxide mineral formation was not an important process for Co removal in the Ross Sea surface waters. If so, these uptake rate measurements can be interpreted as approximations of the rate of assimilation of dissolved Co by the phytoplankton community and any particle-associated bacterial communities. In addition, we observed a near linear relationship between Co uptake and time over $24 \mathrm{~h}$, suggesting that uptake rates are relatively constant over a diel cycle in this region (Station NX7, $30 \mathrm{~m}$ seawater: \% uptake at 1, 3, 5.2, $15.5 \mathrm{~h}$ timepoints was $0.12,0.25,0.48$, and $1.18 \%$, respectively). Overall, these Ross Sea cobalt uptake rates are more than 6-fold higher than cobalt uptake rates measured in the Peru Upwelling region, which also has relatively abundant and labile cobalt and high productivity (Saito et al., 2004). Hence while we argue below that ecological stoichiometries suggest $\mathrm{Zn}$ may dominate cambialistic nutrition, cobalt uptake is still quite pronounced in the Ross Sea. 
It should be noted that uptake rates discussed here were calculated assuming that the radiotracer had equilibrated with the entire dissolved Co pool on the timescale of days to weeks. However, it is likely that there are $\mathrm{Co}$ (III) complexes in seawater (e.g., vitamin $\mathrm{B}_{12}$ ) for which dissociation is extremely slow such that their equilibration with the radiotracer was incomplete. As a result, the rate measurements discussed here are likely upper limits. If uptake rates are calculated assuming that the radiotracer equilibrated only with the measured labile cobalt fraction, the relative trends observed with depth and between stations are broadly similar.

Figure 8 shows that high Co uptake rates were generally found at depths shallower than $20 \mathrm{~m}$ (gray dots, Fig. 8a and b). Since the uptake rate incubations were all conducted at the same irradiance ( $\sim 20 \%$ surface), it is possible that uptake rates in deeper samples may reflect some photoinhibition. However, higher biological algal pigment concentrations in the Ross Sea are generally found in shallower depths, (Figs. 4, 8), hence higher Co uptake rates in nearsurface waters are not unexpected. As shown in Fig. 8, higher Co uptake rate was generally correlated with elevated pigment concentrations. There were some areas where high 19hexanolyoxyfucoxanthin (19-Hex), a haptophyte indicator pigment that is strongly correlated with Phaeocystis antarctica in the Ross Sea (DiTullio et al., 2003), coincided with high Co uptake rates (e.g., Fig. 8c, NX1), but generally, Co uptake rates appeared to correlate most strongly with fucoxanthin concentrations (fuco, a proxy for diatom biomass in the Ross Sea, Fig. 8a). This might suggest that diatoms are responsible for more uptake of Co than Phaeocystis antarctica and that on balance, Co uptake by diatoms may be more efficient than uptake by Phaeocystis. As discussed above, $P$. antarctica and several diatom species have been shown to use Co in place of $\mathrm{Zn}$, although the degree to which Co can replace $\mathrm{Zn}$ varies among diatom species (Sunda and Huntsman, 1995; Saito and Goepfert, 2008). However, even those diatoms that do not substitute Co for $\mathrm{Zn}$ still actively assimilate dissolved Co (Timmermans et al., 2001). Also, the Co requirements of $P$. antarctica are satisfied at lower concentrations relative to some diatoms (Saito and Goepfert, 2008), supporting the idea that diatoms may be responsible for more cobalt uptake than $P$. antarctica. Due to the interrelated biochemistries and transporter affinities for $\mathrm{Co}$ and $\mathrm{Zn}$, it is likely that Co uptake rates may also be driven in part by $\mathrm{Zn}$ concentrations. Since biological uptake and utilization of $\mathrm{Co}$ and $\mathrm{Zn}$ are so closely tied, future research on $\mathrm{Zn}$ abundances, uptake rates, and the proteins responsible for biological substitution between these micronutrients in polar environments would improve our understanding of cobalt uptake in the Ross Sea.

\subsection{Ecological stoichiometry of cobalt inferred from correlation with phosphate, and comparison with $\mathrm{Cd}$ and $\mathrm{Zn}$ stoichiometries}

Phytoplankton uptake and subsequent remineralization of biomass result in the removal and addition of bioactive metals and phosphorus at ratios reflective of the aggregrate stoichiometry of the phytoplankton and microbial community. The sinking of organic material creates a biochemical circulation of elements that is superimposed upon physical circulation processes (Redfield et al., 1963). Based on the extent to which this biochemical circulation modifies the composition of seawater, the slope of the dissolved nutrient to phosphate relationship can reflect the aggregate stoichiometry of biological processes. For example, Redfield et al. (1963) observed similarities between the ratios of seawater $\mathrm{NO}_{3}^{-}: \mathrm{PO}_{4}^{3-}$ distributions and the elemental N:P composition of marine plankton (Redfield et al., 1963), and more recently the cellular metal contents of phytoplankton have been compared with trace metal abundances in seawater (e.g., Sunda and Huntsman, 1995, 2000; Fitzwater et al., 2000; Saito and Moffett, 2002; Ho et al., 2003; Saito et al., 2004; Noble et al., 2008; Lane et al., 2009). This characterization of elemental stoichiometries in nature has been termed "ecological stoichiometry", defined broadly as "the balance of multiple chemical substances in ecological interactions and processes" (Sterner and Elser, 2002). Correlations between dissolved $\mathrm{Cd}$ and $\mathrm{PO}_{4}^{3-}$ or between dissolved $\mathrm{Zn}$ and silicic acid, have long been recognized as oceanographically important relationships (Boyle et al., 1976; Bruland, 1980), leading to the application of $\mathrm{Cd}$ as a paleoproxy for seawater phosphate (Boyle, 1988).

Recent studies have observed correlations between dissolved cobalt and phosphate concentrations in shallow waters (e.g. Sunda and Huntsman, 1995; Saito and Moffett, 2002; Saito et al., 2004; Noble et al., 2008), implying the importance of micronutrient processes over earlier suggestions that atmospheric input and scavenging processes dominate the oceanic distribution of cobalt (Whitfield and Turner, 1987). Yet explanations for these linear metal:macronutrient relationships and, in particular, apparent "kinks" in these linear relationships (Boyle et al., 1981; Boyle, 1988; Frew and Hunter, 1992, 1995; Saager and de Baar, 1993; de Baar et al., 1994; Cullen, 2006), have arguably not reached a consensus due to the presence of multiple processes and subtle complexities such as: (1) limited knowledge of the underlying biochemistries; (2) the influence of iron deficiency, which depresses phytoplankton growth rate but not metal uptake, resulting in changes in metal:P ratios through a process called growth rate dilution (Sunda and Huntsman, 2000; Cullen et al., 2003; Cullen, 2006; Lane et al., 2009), as well as causing upregulation of ferrous iron transporters that also transport other divalent cations (Lane et al., 2008); (3) biochemical substitution of $\mathrm{Zn}, \mathrm{Cd}$, or Co, for example, in the active sites of metalloenzymes (Morel et al., 1994; Saito et 
Table 2. Relationship between cadmium and zinc versus phosphate in the Ross Sea ${ }^{\mathrm{a}}$.

\begin{tabular}{|c|c|c|c|}
\hline Geographic Location & $\begin{array}{l}\text { Depth range } \\
\text { (m) }\end{array}$ & $\begin{array}{l}\Delta \mathrm{M}: \Delta \mathrm{P} \\
\mu \mathrm{mol} \mathrm{mol}\end{array}$ & $r^{2}$ \\
\hline Ross Sea $\left(\mathrm{PO}_{4}^{3-}<1 \mu \mathrm{M}\right)^{\mathrm{b}}$ & $0.5-40$ & 178 (Cadmium) & 0.79 \\
\hline Ross Sea $\left(\mathrm{PO}_{4}^{3-}>1 \mu \mathrm{M}\right)^{\mathrm{b}}$ & $15-375$ & 606 (Cadmium) & 0.91 \\
\hline Ross Sea $\left(\mathrm{PO}_{4}^{3-}<1.5 \mu \mathrm{M}\right)^{\mathrm{b}}$ & $0.5-40$ & 509 (Zinc) & 0.95 \\
\hline Ross Sea $\left(\mathrm{PO}_{4}^{3-}>1.5 \mu \mathrm{M}\right)^{\mathrm{b}}$ & $20-375$ & 7580 (Zinc) & 0.72 \\
\hline Subarctic Pacific ${ }^{\mathrm{c}}\left(\mathrm{PO}_{4}^{3-}<1.2 \mu \mathrm{M}\right)$ & $20-150$ & 450 (Cadmium) & 0.87 \\
\hline Subarctic Pacific ${ }^{\mathrm{c}}\left(\mathrm{PO}_{4}^{3-}>1.2 \mu \mathrm{M}\right)$ & $>150$ & 280 (Cadmium) & 0.93 \\
\hline Subarctic Pacific ${ }^{\mathrm{c}}\left(\mathrm{PO}_{4}^{3-}<1.2 \mu \mathrm{M}\right)$ & $20-150$ & $251(\mathrm{Zinc})$ & 0.77 \\
\hline Subarctic Pacific ${ }^{\mathrm{c}}\left(\mathrm{PO}_{4}^{3-}>1.2 \mu \mathrm{M}\right)$ & $>150$ & 4620 (Zinc) & 0.86 \\
\hline
\end{tabular}

a Relationships shown in Fig. 9.

b Data from Fitzwater et al. (2000).

c Data from Martin et al. (1989); inclusive of T5, T6, T8; based on Sunda and Huntsman (1995).

al., 2008); and (4) the role of organic ligands in controlling metal bioavailability (Bruland and Lohan, 2003). These issues will be discussed below in the context of our Ross Sea data.

In the Ross Sea we estimate a seawater $\mathrm{Co}: \mathrm{PO}_{4}^{3-}$ ecological stoichiometry of $37.6 \mu \mathrm{mol} \mathrm{mol}^{-1}$ based on a two-way linear regression of the dissolved species concentrations using the vertical profile datasets inclusive of all depths and both sampling seasons (Fig. 6a, Table 1; a one-way regression yields a similar value of $28.3 \mu \mathrm{mol} \mathrm{mol}^{-1}$ with $r^{2}$ of $0.75)$. This value is quite similar to the dissolved $\mathrm{Co}: \mathrm{PO}_{4}^{3-}$ ratios of $35-40 \mu \mathrm{mol} \mathrm{mol}^{-1}$ observed in the upper $150 \mathrm{~m}$ of the subarctic Pacific (Martin et al., 1989; Sunda and Huntsman, 1995). However, other regions such as the Eastern Tropical Pacific and Equatorial Atlantic display $\mathrm{Co}: \mathrm{PO}_{4}^{3-}$ stoichiometries that are approximately an order of magnitude higher than the Ross Sea and subarctic Pacific ratios (248 and $560 \mu \mathrm{mol} \mathrm{mol}^{-1}$; Saito and Moffett, 2002; Saito et al., 2004). The juxtaposition of an inter-seasonal coherence for seawater $\mathrm{Co}: \mathrm{PO}_{4}^{3-}$ ecological stoichiometry (where both seasons data falls along a single line) in the Ross Sea relative to the large geographic variability in $\mathrm{Co}: \mathrm{PO}_{4}^{3-}$ stoichiometries described above (Table 1) implies that the organization of dissolved cobalt in the water column occurs on timescales that are longer than seasonal processes, but shorter than that of large-scale circulation processes. This rough timescale is also consistent with the observations of lack of scavenging and uptake rates described in Sects. 3.6 and 3.4, respectively.

The ecological stoichiometry of Co needs to be considered in conjunction with those of $\mathrm{Zn}$ and $\mathrm{Cd}$ because of the biochemical substitution within enzymes as described in the Introduction. The presence of correlations of both dissolved $\mathrm{Co}$ and $\mathrm{Zn}$ with phosphate have been described by Sunda and Huntsman in shallow waters of the subarctic Pacific as evi- dence for biological uptake and remineralization (Martin et al., 1989; Sunda and Huntsman, 1995). In that region the dissolved $\mathrm{Zn}$ and $\mathrm{PO}_{4}^{3-}$ relationship showed a distinct kink causing two stoichiometries: a dissolved $\mathrm{Zn}: \mathrm{PO}_{4}^{3-}$ ratio of $\sim 4600 \mu \mathrm{mol} \mathrm{mol}^{-1}$ below $\sim 150 \mathrm{~m}$ depth (where $\mathrm{PO}_{4}^{3-}>\sim$ $1.2 \mu \mathrm{M}$ ), and a much lower $\mathrm{Zn}: \mathrm{PO}_{4}^{3-}$ ratio of $\sim 250$ in shallow waters (see Fig. 9 and Table 2; data from Martin et al., 1989). Interestingly, dissolved Co was correlated with $\mathrm{PO}_{4}^{3-}$ only in the shallow waters, which Sunda and Huntsman (1995) attributed to the biochemical substitution of Co for some of the biological $\mathrm{Zn}$ demand in the euphotic zone. These authors estimated a larger nutritional role of $\mathrm{Zn}$ relative to Co in shallow waters, based on ecological stoichiometry ratios for dissolved $\mathrm{Zn}: \mathrm{PO}_{4}^{3-} / \mathrm{Co}: \mathrm{PO}_{4}^{3-}$ of 6:1-10:1. However, they also pointed out that the $>100$-fold increase in dissolved $\mathrm{Co}: \mathrm{Zn}$ concentrations between the nutricline and surface waters could also contribute to growth of phytoplankton with distinct Co requirements, such as the coccolithophore $E$. huxleyi and cyanobacteria (Sunda and Huntsman, 1995; Saito et al., 2002). No linear relationship between $\mathrm{Co}: \mathrm{PO}_{4}^{3-}$ was observed in deeper waters of the subarctic Pacific, likely due to the influence of scavenging (see below).

We have performed a similar comparison of ecological stoichiometries in the Ross Sea, using our dissolved Co data and the dissolved $\mathrm{Zn}$ and $\mathrm{Cd}$ data reported from the austral summer of 1990 by Fitzwater et al. (2000). Here Zn and $\mathrm{Cd}$ both showed correlations with phosphate, with $\mathrm{Zn}$ showing a kink at $\sim 1.5 \mu \mathrm{MPO}_{4}^{3-}$ to a lower $\mathrm{Zn}: \mathrm{PO}_{4}^{3-}$ ratio and $\mathrm{Cd}$ showing a kink at $\sim 1 \mu \mathrm{M} \mathrm{PO}_{4}^{3-}$ (Fig. 9g and $\mathrm{h}$; Table 2). The calculated dissolved phase ecological stoichiometries were roughly similar to those of the subarctic

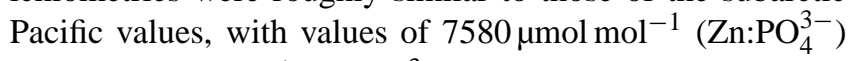
and $606 \mu \mathrm{mol} \mathrm{mol}^{-1}\left(\mathrm{Cd}: \mathrm{PO}_{4}^{3-}\right)$ in the nutricline and below, 
Table 3. Cobalt uptake rates and associated parameters. Errors given are one standard deviation unless noted.

\begin{tabular}{|c|c|c|c|c|c|c|c|c|c|c|c|c|}
\hline Station & Local date & Lat & Long & depth (m) & $\begin{array}{l}\text { Avg. } \%^{57} \text { Co } \\
\text { uptake day }\end{array}$ & $\begin{array}{l}\text { total Co } \\
\text { conc. }(\mathrm{pM})\end{array}$ & $\begin{array}{r}\text { labile Co } \\
\text { conc. }(\mathrm{pM})\end{array}$ & $\begin{array}{c}\text { Co uptake } \\
\left(\mathrm{pmol} \mathrm{L}^{-1} \text { day }^{-1}\right)\end{array}$ & $\begin{array}{l}\text { Pigment } \\
\text { Depth }[\mathrm{m}]\end{array}$ & $\begin{array}{l}\text { Fuco } \\
\left(\mathrm{ng} \mathrm{L}^{-1}\right)\end{array}$ & $\begin{array}{l}\text { 19-Hex } \\
\left(\mathrm{ng} \mathrm{L}^{-1}\right)\end{array}$ & $\begin{array}{l}\text { Chl- } a \\
\left(\mathrm{ng} \mathrm{L}^{-1}\right)\end{array}$ \\
\hline \multicolumn{13}{|c|}{ CORSACS-1 } \\
\hline \multirow[t]{2}{*}{ NX1 } & 29 Dec 2005 & $77.40^{\circ} \mathrm{S}$ & $179.56^{\circ} \mathrm{E}$ & 10 & $5.56 \pm 0.69$ & $34.07 \pm 0.78$ & n.d. & $1.90 \pm 0.24$ & 10 & 360 & 1257 & 3459 \\
\hline & & & & 30 & $0.70 \pm 0.07$ & $24.62 \pm 1.35$ & n.d. & $0.17 \pm 0.02$ & 36 & 186 & 2810 & 7788 \\
\hline \multirow[t]{4}{*}{ Stn 18} & 31 Dec 2005 & $76.44^{\circ} \mathrm{S}$ & $169.43^{\circ} \mathrm{E}$ & 10 & $0.48 \pm 0.09$ & $28.22 \pm 0.37$ & n.d. & $0.13 \pm 0.02$ & 8 & 91 & 75 & 669 \\
\hline & & & & 40 & $0.43 \pm 0.13$ & $32.63 \pm 0.64$ & n.d. & $0.14 \pm 0.04$ & 36 & 140 & 277 & 1426 \\
\hline & & & & 75 & $0.18 \pm 0.08$ & $51.39 \pm 0.71$ & n.d. & $0.09 \pm 0.04$ & 83 & 81 & 234 & 1044 \\
\hline & & & & 130 & $0.02 \pm 0.01$ & n.d. & n.d. & n.d. & 100 & 59 & 160 & 694 \\
\hline \multirow[t]{2}{*}{ Stn 37} & 5 Jan 2006 & $76.30^{\circ} \mathrm{S}$ & $169.60^{\circ} \mathrm{W}$ & 10 & $4.61 \pm 1.22$ & $35.34 \pm 2.09$ & n.d. & $1.63 \pm 0.44$ & 10 & 347 & 1255 & 1900 \\
\hline & & & & 30 & $2.13 \pm 0.27$ & $35.89 \pm 1.60$ & n.d. & $0.76 \pm 0.10$ & 33 & 321 & 1040 & 1894 \\
\hline \multirow[t]{2}{*}{ Stn 43/NX6 } & 7 Jan 2006 & $75.60^{\circ} \mathrm{S}$ & $176.37^{\circ} \mathrm{W}$ & 10 & $1.22 \pm 0.11$ & $32.98 \pm 1.22$ & n.d. & $0.40 \pm 0.04$ & 11 & 796 & 466 & 3148 \\
\hline & & & & 30 & $0.99 \pm 0.24$ & $34.68 \pm 2.41$ & n.d. & $0.34 \pm 0.09$ & 25 & 619 & 419 & 2514 \\
\hline \multirow[t]{2}{*}{ Stn $51 / N X 7$} & 9 Jan 2006 & $75.60^{\circ} \mathrm{S}$ & $170.59^{\circ} \mathrm{E}$ & 10 & $1.32 \pm 0.26$ & $26.28 \pm 2.74$ & n.d. & $0.35 \pm 0.07$ & 11 & 406 & 217 & 1458 \\
\hline & & & & 30 & $1.52 \pm 0.05$ & $29.86 \pm 1.53$ & n.d. & $0.45 \pm 0.01$ & 35 & 454 & 282 & 1722 \\
\hline \multirow[t]{6}{*}{ Stn $61 / \mathrm{NX} 8$} & 12 Jan 2006 & $77.30^{\circ} \mathrm{S}$ & $175.44^{\circ} \mathrm{W}$ & 10, live & $1.41 \pm 0.14$ & $27.14 \pm 3.26$ & n.d. & $0.38 \pm 0.04$ & 12 & 196 & 266 & 723 \\
\hline & & & & 10 , glut kill & $0.03 \pm 0.001^{*}$ & & & $0.01 \pm 0.00$ & & & & \\
\hline & & & & 10 , heat kill & $0.11 \pm 0.005^{*}$ & & & $0.03 \pm 0.00$ & & & & \\
\hline & & & & 30, live & $0.25 \pm 0.02$ & $38.58 \pm 1.33$ & n.d. & $0.10 \pm 0.01$ & 26 & 133 & 345 & 819 \\
\hline & & & & 30 , glut kill & $0.01 \pm 0001^{*}$ & & & $0.00 \pm 0.00$ & & & & \\
\hline & & & & 30 , heat kill & $0.15 \pm 0.007^{*}$ & & & $0.06 \pm 0.00$ & & & & \\
\hline \multirow[t]{2}{*}{ Stn $67 / N X 9$} & 14 Jan 2006 & $78.39^{\circ} \mathrm{S}$ & $164.45^{\circ} \mathrm{W}$ & 10 & $0.32 \pm 0.21$ & $40.10 \pm 2.70$ & n.d. & $0.13 \pm 0.09$ & 12 & 136 & 329 & 727 \\
\hline & & & & 30 & $0.15 \pm 0.04$ & $39.60 \pm 2.66$ & n.d. & $0.06 \pm 0.02$ & 26 & 100 & 354 & 854 \\
\hline \multirow[t]{2}{*}{ Stn 86} & 20 Jan 2006 & $74.40^{\circ} \mathrm{S}$ & $168.52^{\circ} \mathrm{E}$ & 10 & $3.16 \pm 0.16$ & $32.02 \pm 2.55$ & n.d. & $1.01 \pm 0.06$ & 10 & 1174 & 46 & 1377 \\
\hline & & & & 30 & $3.28 \pm 0.88$ & $24.94 \pm 1.23$ & n.d. & $0.82 \pm 0.22$ & 38 & 559 & 60 & 897 \\
\hline \multirow[t]{2}{*}{ Stn 95} & 22 Jan 2006 & $75.00^{\circ} \mathrm{S}$ & $166.00^{\circ} \mathrm{E}$ & 10 & $16.14 \pm 0.70$ & $14.38 \pm 0.60$ & n.d. & $2.32 \pm 0.10$ & 8 & 1612 & 37 & 1572 \\
\hline & & & & 30 & $1.14 \pm 0.05$ & $31.67 \pm 0.31$ & n.d. & $0.36 \pm 0.02$ & 28 & 713 & 93 & 1082 \\
\hline \multirow[t]{2}{*}{ Stn 97} & 22 Jan 2006 & $74.50^{\circ} \mathrm{S}$ & $166.00^{\circ} \mathrm{E}$ & 10 & $12.82 \pm 1.04$ & $13.75 \pm 1.53$ & n.d. & $1.76 \pm 0.16$ & 8 & 805 & 25 & 861 \\
\hline & & & & 30 & $0.81 \pm 0.07$ & $35.33 \pm 2.59$ & n.d. & $0.29 \pm 0.02$ & 33 & 634 & 66 & 1093 \\
\hline \multicolumn{13}{|c|}{ CORSACS-2 } \\
\hline \multirow[t]{4}{*}{ NX14 } & 18 Nov 2006 & $75.93^{\circ} \mathrm{S}$ & $178.36^{\circ} \mathrm{E}$ & 17 & $0.69 \pm 0.14$ & $47.23 \pm 1.94$ & 14.88 & $0.33 \pm 0.07$ & 15 & 195 & 484 & 1348 \\
\hline & & & & 37 & $0.99 \pm 0.06$ & $49.47 \pm 2.08$ & 17.45 & $0.49 \pm 0.03$ & 35 & 215 & 439 & 1379 \\
\hline & & & & 57 & $1.06 \pm 0.34$ & $45.73 \pm 1.94$ & 19.59 & $0.49 \pm 0.15$ & 60 & 192 & 445 & 1256 \\
\hline & & & & 97 & $0.40 \pm 0.06$ & $52.86 \pm 1.65$ & 24.66 & $0.21 \pm 0.03$ & 100 & 50 & 121 & 477 \\
\hline \multirow[t]{4}{*}{ NX15 } & 20 Jan 2006 & $76.93^{\circ} \mathrm{S}$ & $173.96^{\circ} \mathrm{E}$ & 17 & $0.34 \pm 0.01$ & $50.97 \pm 2.61$ & 28.16 & $0.17 \pm 0.01$ & 15 & 161 & 352 & 1816 \\
\hline & & & & 37 & $0.45 \pm 0.07$ & $47.25 \pm 3.45$ & 15.93 & $0.21 \pm 0.03$ & 35 & 202 & 370 & 1822 \\
\hline & & & & 57 & $0.33 \pm 0.08$ & $50.09 \pm 2.40$ & 45.18 & $0.17 \pm 0.04$ & 60 & 123 & 284 & 1488 \\
\hline & & & & 97 & $0.42 \pm 0.01$ & $41.44 \pm 0.92$ & 28.14 & $0.17 \pm 0.00$ & 100 & 143 & 276 & 1383 \\
\hline \multirow[t]{4}{*}{ NX17 } & 26 Nov 2006 & $76.50^{\circ} \mathrm{S}$ & $178.55^{\circ} \mathrm{E}$ & 17 & $0.58 \pm 0.13$ & $42.64 \pm 1.33$ & 5.49 & $0.25 \pm 0.06$ & 15 & 884 & 1827 & 3881 \\
\hline & & & & 37 & $0.39 \pm 0.11$ & $40.83 \pm 1.79$ & 11.81 & $0.16 \pm 0.04$ & 36 & 894 & 1394 & 3667 \\
\hline & & & & 57 & $0.50 \pm 0.01$ & $52.39 \pm 2.10$ & 11.54 & $0.26 \pm 0.01$ & 60 & 520 & 593 & 2385 \\
\hline & & & & 97 & $0.23 \pm 0.01$ & $57.37 \pm 3.23$ & 9.73 & $0.13 \pm 0.01$ & 100 & 182 & 251 & 1210 \\
\hline \multirow[t]{4}{*}{ NX20 } & 3 Dec 2006 & $76.50^{\circ} \mathrm{S}$ & $180.0^{\circ} \mathrm{W}$ & 17 & $0.98 \pm 0.05^{*}$ & $51.08 \pm 3.53$ & 10.82 & $0.50 \pm 0.03$ & 17 & 527 & 2134 & 5394 \\
\hline & & & & 37 & $0.71 \pm 0.04^{*}$ & $42.15 \pm 2.61$ & 6.55 & $0.30 \pm 0.02$ & 39 & 143 & 683 & 2514 \\
\hline & & & & 57 & $0.33 \pm 0.02^{*}$ & $51.08 \pm 3.74$ & 10.13 & $0.17 \pm 0.01$ & 60 & 164 & 873 & 2807 \\
\hline & & & & 97 & $0.11 \pm 0.06^{*}$ & $51.77 \pm 2.16$ & 16.28 & $0.06 \pm 0.00$ & 100 & 145 & 856 & 2422 \\
\hline
\end{tabular}

* denotes where only single incubations were conducted. Error given is 5\% counting error rather than standard deviation. n.d. denotes no data available.

and of $509 \mu \mathrm{mol} \mathrm{mol}^{-1}\left(\mathrm{Zn}: \mathrm{PO}_{4}^{3-}\right)$ and $178 \mu \mathrm{mol} \mathrm{mol}^{-1}$ $\left(\mathrm{Cd}: \mathrm{PO}_{4}^{3-}\right)$ in shallow waters $(\leq 40 \mathrm{~m}$; Table 2$)$. Cobalt analyses were also included in the Fitzwater et al. (2000) study; however, no clear relationship between $\mathrm{Co}$ and $\mathrm{P}$ was observed. This may reflect limited analytical precision for Co or the recently documented artifact arising from cobaltbinding ligands, which necessitate UV-irradiation of samples prior to dissolved Co determination since the complexes do not dissociate at pH 2 (Saito and Schneider, 2006; Bruland, 2010), although this analytical issue would presumably apply to the subarctic Pacific dataset used here as well, which does not appear to have any precision issues (Table 1; Martin et al.,1989). While dissolved $\mathrm{Zn}: \mathrm{PO}_{4}^{3-}$ and $\mathrm{Cd}: \mathrm{PO}_{4}^{3-}$ ratios are much lower in shallow waters relative to depth, the dissolved Co: $\mathrm{PO}_{4}^{3-}$ stoichiometry is relatively low $\left(37.6 \mu \mathrm{mol} \mathrm{mol}^{-1}\right)$ and constant throughout the water column based on our 2005/2006 data, in contrast to the subarctic Pacific data where the $\mathrm{Co}: \mathrm{PO}_{4}^{3-}$ relationship breaks down below shallow waters (Figs. 9d and 10b). While the Fitzwater et al. (2000) data are from an earlier expedition (summer 1990), we assume some consistency of the Ross Sea phytoplankton stoichiometry for the purpose of our comparisons.

The estimated ecological stoichiometries for dissolved Co, $\mathrm{Cd}$, and $\mathrm{Zn}$ in the Ross Sea can be compared to the trace metal requirements of phytoplankton measured by physiological studies under growth rate limiting conditions (Sunda and Huntsman, 1995, 2000), as shown in Fig. 10. Of particular interest, the deep water dissolved $\mathrm{Zn}: \mathrm{PO}_{4}^{3-}$ stoichiometries of both the Ross Sea and subarctic Pacific were in great excess of the minimum $\mathrm{Zn}$ quotas required for optimum growth of three eukaryotic phytoplankton (Emiliania 

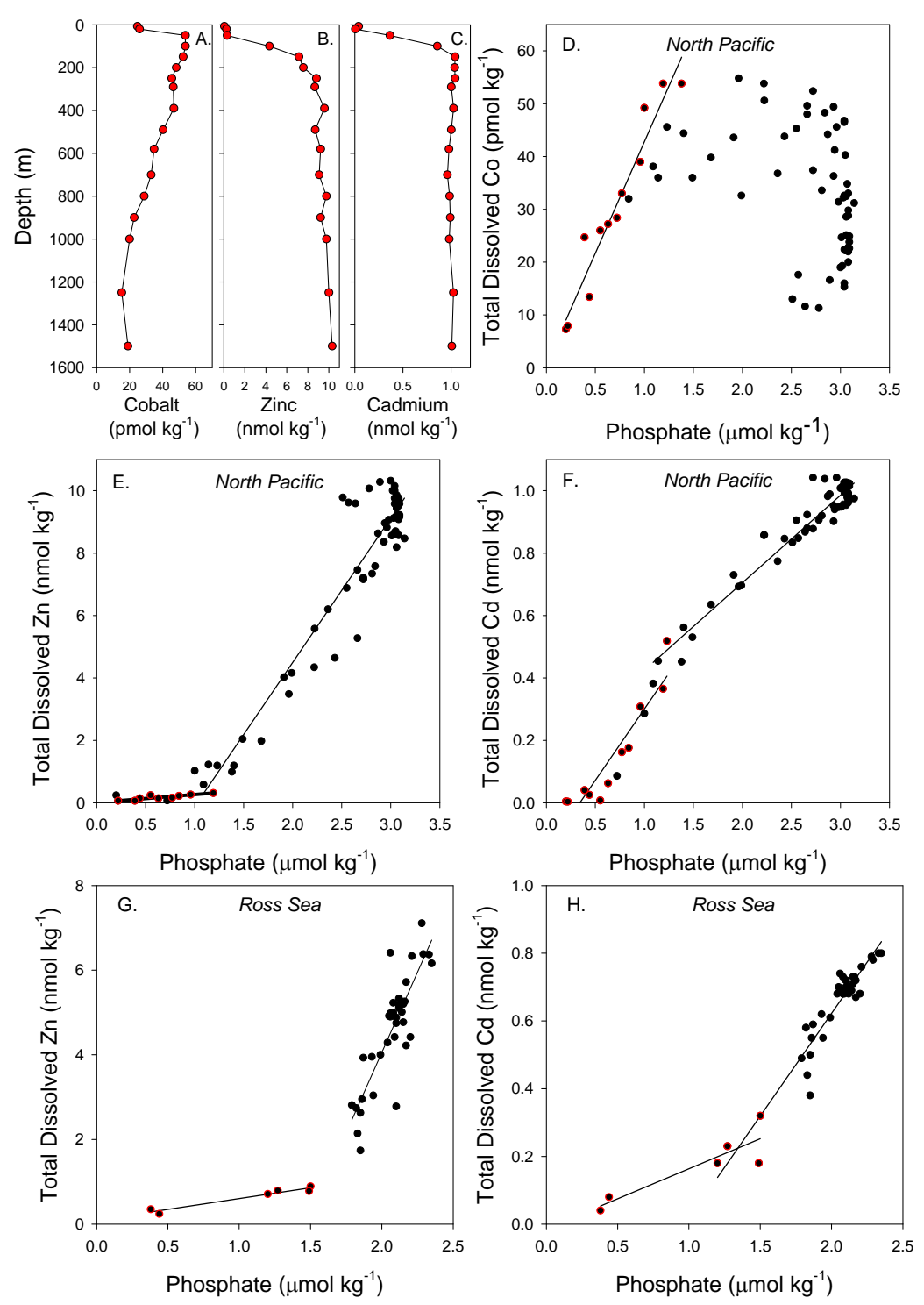

Fig. 9. Examination of relationships between $\mathrm{Co}, \mathrm{Cd}$, and $\mathrm{Zn}$ and phosphate in the subarctic Pacific and Ross Sea in previous studies (Martin et al., 1989; Fitzwater et al., 2000). (A-C) Vertical profiles of Co, Zn, and Cd in the subarctic Pacific/Gulf of Alaska (Station T8) from Martin et al. (1989), with Co showing the influence of scavenging at intermediate depths. (D) A correlation of subarctic Pacific cobalt with phosphate was present in the upper $100 \mathrm{~m}$ of several vertical profiles (red outline), whereas Co from below the euphotic zone to $4000 \mathrm{~m}$ depth showed the influence of scavenging with a downward curl relative to phosphate (see scavenging vector in Fig. 7). (E-F) The subarctic Pacific $\mathrm{Zn}$ vs. $\mathrm{PO}_{4}^{3-}$ and $\mathrm{Cd}$ vs. $\mathrm{PO}_{4}^{3-}$ showed a concave and convex kink respectively, where the datasets were separated into shallow (red outline) and deep (black) and the estimated stoichiometries are shown in Table 2. (G-H) Shallow (red outline) and deep (black) $\mathrm{Zn}_{\mathrm{vs} .} \mathrm{PO}_{4}^{3-}$ and Cd vs. $\mathrm{PO}_{4}^{3-}$ relationships in the Ross Sea using data from Fitzwater et al. (1990), with linear regressions shown.

huxleyi, Thalassiosira oceanica, and Thalassiosira pseudonana), while the shallow $\mathrm{Zn}: \mathrm{P}$ ratio was in excess of the requirements of the small diatom $T$. oceanica but not those of the larger diatom T. pseudonana. These variations in dissolved $\mathrm{Zn}$ requirements have been shown to be related to the higher surface area to volume ratio that accompanies smaller cell size, where uptake rates approach diffusion limitation at low $\mathrm{Zn}^{2+}$ concentrations (Sunda and Huntsman,
1992, 1995). This comparison suggests that the $\mathrm{Zn}$ availability could influence phytoplankton species composition in the Ross Sea by selecting for smaller diatoms that have lower cellular $\mathrm{Zn}$ requirements. In contrast, our estimated $\mathrm{Co}: \mathrm{PO}_{4}^{3-}$ ecological stoichiometry value was found to be below the phytoplankton growth requirements when in the absence of added $\mathrm{Zn}$ in the three strains listed above ( $\sim 200-$ $1000 \mu \mathrm{mol} \mathrm{Co:mol} \mathrm{P;} \mathrm{Sunda} \mathrm{and} \mathrm{Huntsman,} \mathrm{1995).} \mathrm{These}$ 


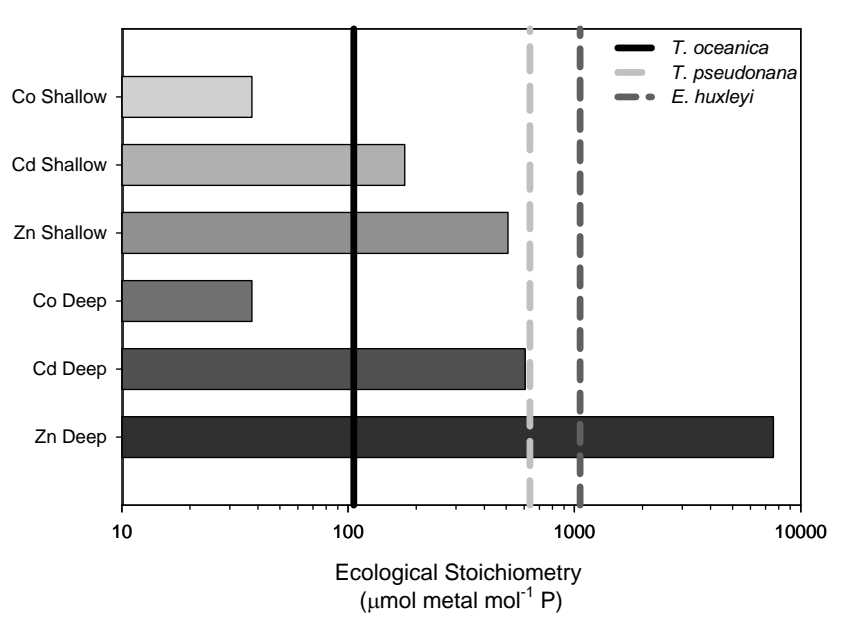

Fig. 10. Ecological stoichiometries from dissolved $\mathrm{Zn}, \mathrm{Cd}$, and $\mathrm{Co}$ in shallow water $(<40 \mathrm{~m})$ and intermediate depths $(50 \mathrm{~m}-500 \mathrm{~m})$ in the Ross Sea (horizontal bars, Tables 1 and 2; Co data from this study, Zn and Cd data from Fitzwater et al., 2000) compared to laboratory estimates of cellular stoichiometries of $\mathrm{Zn}: \mathrm{P}$ below which phytoplankton growth limitation is observed (vertical lines, when no cobalt is added; data from Sunda and Huntsman, 1995). Co:P growth limiting stoichiometries (when no zinc is added) are quite similar to the $\mathrm{Zn}: \mathrm{P}$ stoichiometries shown, with the exception that both diatoms (T. oceanica and T. pseudonana) do not reach the maximal growth rates with no zinc added (Sunda and Huntsman, 1995). These results imply that low $\mathrm{Zn}: \mathrm{PO}_{4}^{3-}$ stoichiometries in shallow waters could phytoplankton community composition in the Ross Sea.

observations imply the need for $\mathrm{Zn}$ nutrition in the $\mathrm{Zn} / \mathrm{Co}$ cambialistic enzymes due to low Co abundance in the Ross Sea. Similarly, Zn and Co physiological studies with a culture of Phaeocystis antarctica showed optimal growth rates and cell yields with $\mathrm{Zn}$ rather than Co (Saito and Goepfert, 2008). Together these calculations provide evidence for a greater overall use of zinc relative to cobalt in the shallow waters of the Ross Sea, with a ratio of dissolved $\mathrm{Zn}$ :Co stoichiometries of 17:1 ( $\left.\mathrm{Zn}: \mathrm{PO}_{4}^{3-} / \mathrm{Co}: \mathrm{PO}_{4}^{3-}\right)$. This ratio suggests that Ross Sea phytoplankton have an even greater nutritional reliance on $\mathrm{Zn}$ versus $\mathrm{Co}$, relative to the subarctic Pacific (Zn:Co 6:1-10:1, see above). However, the particularly intense primary productivity of the Ross Sea likely maintains selection pressure for biochemical substitution of Co, Cd and Zn. For example, Capodaglio et al. (1998) report significant drawdown of $\mathrm{Cd}$ ( $>5$ fold) during the seasonal progression in Terra Nova Bay of the Ross Sea, likely caused by the tremendous diatom blooms and resultant $\mathrm{CO}_{2}$ drawdown observed there (Arrigo et al., 1999). It seems likely that under these highly productive and lowered $\mathrm{CO}_{2}$ conditions, cambialistic carbonic anhdyrase enzymes have an important ecological and biogeochemical function.
An intriguing aspect of the $\mathrm{Co}$ and $\mathrm{PO}_{4}^{3-}$ relationship in the Ross Sea is the lack of an obvious kink in the vertical profile dataset (Fig. 6a), in contrast to $\mathrm{Cd}$ and $\mathrm{Zn}$ which both showed clear kinks in the Ross Sea (Fig. 9g and h; Fitzwater et al., 2000). The causes of the kink in the relationship between $\mathrm{Cd}$ and phosphate has been the subject of significant discussion in recent years (Boyle, 1988; de Baar, 1994; Elderfield and Rickaby, 2000; Sunda and Huntsman, 2000; Cullen et al., 2003; Cullen, 2006; Ellwood, 2008; Hendry et al., 2008), and we argue here that comparing the relationships of $\mathrm{Co}, \mathrm{Cd}$, or $\mathrm{Zn}$ with phosphate should provide useful insights into the causes behind these kinks. Two previous compelling mechanistic explanations for the $\mathrm{Cd}$ kink involve the influence of either $\mathrm{Zn}$ or $\mathrm{Fe}$ on $\mathrm{Cd}$ uptake by phytoplankton. The $\mathrm{Zn}$ mechanism involves depletion of $\mathrm{Zn}$ by phytoplankton uptake, resulting in an increase in $\mathrm{Cd}$ uptake through induction of phytoplankton $\mathrm{Cd} / \mathrm{Co}$ transporters and replacement of $\mathrm{Cd}$ or Co for $\mathrm{Zn}$ within enzymes (Sunda and Huntsman, 2000). Zn binding ligands also likely contribute to this effect: as dissolved $\mathrm{Zn}$ falls below the $\mathrm{Zn}$ binding ligand concentration, the free zinc concentrations will decrease precipitously. The alternative (or additional) $\mathrm{Fe}$ mechanism involves decreases in the uptake of major cellular elements (e.g., C or P) due to iron growth rate limitation, while maintaining (or increasing) $\mathrm{Cd}$ uptake rates, to create the enhanced cellular Cd:P ratios (Sunda and Huntsman, 2000; Cullen et al., 2003; Cullen, 2006). This process is described as a growth rate dilution effect, where phosphate uptake is more sensitive to growth rate than metal uptake. A recent study provided an additional biochemical mechanism for this phenomenon where iron limitation of a diatom was found to cause an upregulation of ferrous iron transporters, which concurrently resulted in increased transport of other divalent cations such as cadmium (Lane et al., 2008). Both the $\mathrm{Zn}$ depletion and Fe limitation mechanisms result in increased Cd:P ratios in phytoplankton that in turn should deplete dissolved $\mathrm{Cd}$ relative to $\mathrm{P}$ in the upper water column with export and remineralization of particulate material below the euphotic zone. These mechanisms are not necessarily mutually exclusive: while the $\mathrm{Zn}$ mechanism may occur in non-iron limited oceanic areas, both could exist in iron limited regions. These mechanisms are also broadly consistent with Elderfield and Rickaby's "fractionation" concept for the global dissolved $\mathrm{Cd}: \mathrm{PO}_{4}^{3-}$ relationship (2000). Those workers suggested that a preferential incorporation of $\mathrm{Cd}$ relative to $\mathrm{P}$ into the particulate organic matter (POM) occurs $\left((\mathrm{Cd}: \mathrm{P})_{\mathrm{POM}} /(\mathrm{Cd}: \mathrm{P})_{\text {Seawater }}=\alpha, \sim 2.5\right)$, admittedly without invoking a specific mechanism. Elderfield and Rickaby further argue that the kinks are actually better described as curves that can be fit by a modified version of the Rayleigh isotope fraction model.

The finding that $\mathrm{Co}: \mathrm{PO}_{4}^{3-}$ does not show an obvious kink in the vertical profile data from the Ross Sea (Fig. 6a) seems inconsistent with the two mechanisms described above, both of which should result in enhanced Co:P ratios in 

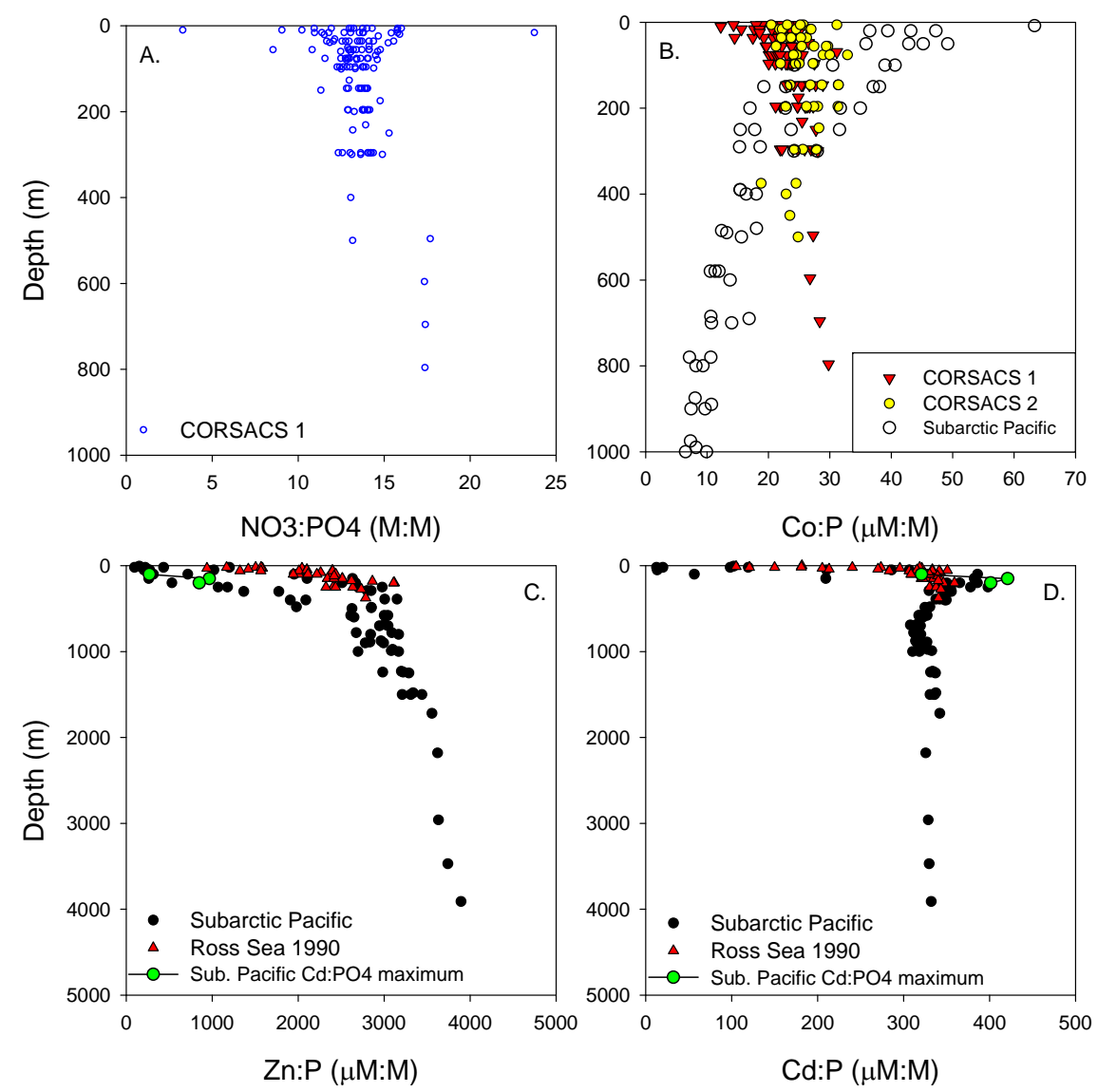

Fig. 11. (A) Comparison of $\mathrm{NO}_{3}^{-}: \mathrm{PO}_{4}^{3-}$ and (B) $\mathrm{Co}: \mathrm{PO}_{4}^{3-}$ ratios with respect to depth from this study (vertical profiles of CORSACS-1 and 2 for $\mathrm{Co}: \mathrm{PO}_{4}^{3-}$ ) show relatively modest variability, with some dissolved $\mathrm{Co}: \mathrm{PO}_{4}^{3-}$ decreases in surface waters. The slope of $\mathrm{NO}_{3}^{-}$plotted against $\mathrm{PO}_{4}^{3-}$ here was 13.4, lower than Redfield ratio consistent with previous Ross Sea findings (Arrigo et al., 1999). Co: $\mathrm{PO}_{4}^{3-}$ ratios from the subarctic Pacific show the influence of scavenging removal at below the euphotic zone. (C-D) In contrast, dissolved $\mathrm{Zn}: \mathrm{PO}_{4}^{3-}$ and $\mathrm{Cd}: \mathrm{PO}_{4}^{3-}$ ratios in the subarctic Pacific (Martin et al., 1989) and Ross Sea (Fitzwater et al., 2000) show large decreases in surface waters, consistent with our argument for a higher $\mathrm{Zn}: \mathrm{P}$ phytoplankton stoichiometry at the base of the euphotic zone contributing to the formation of the $\mathrm{Zn}$ and $\mathrm{Cd}$ kinks. Note the elevated $\mathrm{Cd}: \mathrm{PO}_{4}^{3-}$ ratios at $\sim 100 \mathrm{~m}$ and corresponding small maximum in $\mathrm{Zn}: \mathrm{PO}_{4}^{3-}$ values in the subarctic Pacific shown in green, the former of which we attribute to a biological concentrating mechanism (Noble et al., 2008).

phytoplankton similar to that of Cd:P. Although the inclusion of the surface transect dCo (Fig. 6b) suggests a plateau of $\sim 20 \mathrm{pM}$, perhaps due to depletion of labile Co and a residual of complexed cobalt that is less bioavailable (Fig. 6c and d). There are potentially three explanations for this lack of kink observation in the vertical profile dCo datasets. First, perhaps it is an artifact of temporal variability where a Co kink might have occurred during the 1990 expedition, but was not analytically resolvable at the time. We think this scenario is unlikely given the general similarity of $\mathrm{Co}, \mathrm{Cd}$, and $\mathrm{Zn}$ abundances between these two expeditions. Second, perhaps it is an artifact of comparing a regional $\mathrm{Co}: \mathrm{PO}_{4}^{3-}$ relationship to the global $\mathrm{Cd}: \mathrm{PO}_{4}^{3-}$ relationship, and that a kink might be observed within a larger Co dataset. We also do not think this is the case: while the $\mathrm{Co}: \mathrm{PO}_{4}^{3-}$ relation-

Biogeosciences, 7, 4059-4082, 2010 ship is clearly much more variable (Table 1) than $\mathrm{Cd}: \mathrm{PO}_{4}^{3-}$, the $\mathrm{Cd}: \mathrm{PO}_{4}^{3-}$ kinks are evident in numerous individual sitespecific studies. Third, the most likely explanation is that there is an accumulation of $\mathrm{Zn}$ and $\mathrm{Cd}$ by phytoplankton in excess of their biochemical requirements (at either optimal growth rate or iron-limited growth rate) near the base of the euphotic zone, while cobalt is too scarce to allow excess uptake, as shown in the previous comparison to culture studies (Fig. 10). This is consistent with the observation that the Ross Sea dissolved $\mathrm{Zn}: \mathrm{PO}_{4}^{3-}$ ecological stoichiometry below the nutricline was in great excess of phytoplankton requirements (Fig. 10), and the assumption that the metal requirements for cambialistic enzymes can be considered as the sum of the substitutable metals $(\mathrm{Zn}+\mathrm{Cd}+\mathrm{Co})$, albeit with varying efficiencies for each metal. By this mechanism, excess uptake beyond growth limiting requirements of $\mathrm{Zn}$ (and $\mathrm{Cd}$ ) 
by phytoplankton at the base of the euphotic zone and/or near the chlorophyll maximum followed by sinking and remineralization of high $\mathrm{Zn}: \mathrm{P}$ particulate material out of the euphotic zone would result in eventual surface waters with a lower dissolved $\mathrm{Zn}: \mathrm{PO}_{4}^{3-}$ ratio, and resultant lower phytoplankton cellular Zn:P. Because phytoplankton cellular metal quotas are highly plastic relative to $\mathrm{P}$ quotas, varying by four orders of magnitude for $\mathrm{Zn}$ versus one order or less for $\mathrm{P}$ (Droop, 1974; Sunda and Huntsman, 1992; Bertilsson et al., 2003), this mechanism of excess $\mathrm{Zn}$ uptake seems a plausible explanation for depleting surface waters in $\mathrm{Zn}$ relative to $\mathrm{PO}_{4}^{3-}$. Evidence for excess $\mathrm{Zn}$ uptake in the Ross Sea is shown in Fig. $1 \mathrm{c}$ and d, where both dissolved $\mathrm{Zn}: \mathrm{PO}_{4}^{3-}$ and $\mathrm{Cd}: \mathrm{PO}_{4}^{3-}$ stoichiometries decrease by $\sim 30$-fold in the subarctic $\mathrm{Pa}$ cific and $\sim 3$-fold in the Ross Sea towards surface waters. In contrast, dissolved Co: $\mathrm{PO}_{4}^{3-}$ and $\mathrm{NO}_{3}^{-}: \mathrm{PO}_{4}^{3-}$ ratios do not change appreciably throughout the water column, although there is some decrease in $\mathrm{Co}: \mathrm{PO}_{4}^{3-}$ ratios in the shallowest samples (Fig. 1a and b). We suggest two interrelated reasons for this: first, the high ratio of dissolved $\mathrm{Zn}: \mathrm{Co}$ in the Ross Sea described above likely results in high $\mathrm{Zn}$ uptake and resultant minor Co uptake and use in the cambialistic enzymes within the phytoplankton community, as observed in laboratory culture studies (Sunda and Huntsman, 1995; Lane and Morel, 2000). Second, as mentioned above, these low dissolved $\mathrm{Co}: \mathrm{PO}_{4}^{3-}$ ratios are less than that required for optimal phytoplankton growth without supplementation with $\mathrm{Zn}$ (Sunda and Huntsman, 1995). The result of these two factors is a lack of excess Co uptake relative to $\mathrm{PO}_{4}^{3-}$ at the base of the euphotic zone resulting in the relatively uniform dissolved Co: $\mathrm{PO}_{4}^{3-}$ ratio throughout the water column (Fig. 11), and hence no clear $\mathrm{Co}: \mathrm{PO}_{4}^{3-}$ kink in the vertical profile data (Fig. 6a).

This excess stoichiometry mechanism for $\mathrm{Zn}: \mathrm{P}$ and $\mathrm{Cd}: \mathrm{P}$ kink formation is not mutually exclusive to the previous Fe-limitation and Zn-depletion mechanisms suggested for $\mathrm{Cd}: \mathrm{P}$ kink formation described above. Iron limitation was observed in the Ross Sea during both CORSACS cruises (Bertrand et al., 2007, 2011) and the 1990 expedition (Coale et al., 2003), consistent with the iron-induced $\mathrm{Cd}: \mathrm{PO}_{4}^{3-}$ growth rate dilution kink formation mechanism. Moreover, we measured $\mathrm{Zn}$ speciation in the Ross Sea and found that, in contrast to the North Pacific (Bruland, 1989; Jakuba et al., 2011), Zn-binding ligands were not present in excess of total dissolved $\mathrm{Zn}$ (M. A. Saito, personal communication, 2010). Lack of excess strong ligand has also been observed for Cd in Terra Nova Bay of the Ross Sea (Capodaglio et al., 1998) and $\mathrm{Zn}$ in the Atlantic sector of the Southern Ocean (Baars et al., 2010; Croot et al., 2010). This results in higher concentrations of bioavailable $\mathrm{Zn}$ in shallow waters and with that a lessened contribution to $\mathrm{Cd}: \mathrm{PO}_{4}^{3-}$ kink formation by the $\mathrm{Zn}$ mechanism. This speciation effect is also consistent with dissolved $\mathrm{Zn}: \mathrm{PO}_{4}^{3-}$ ecological stoichiometries found in the Ross Sea as well as the Southern Ocean
(Sunda and Huntsman, 2000) being higher than the subarctic Pacific (Table 2). In addition, the observation of gradually decreasing metal:phosphate ratios higher in the water column (Fig. 11c and d) is more compatible with Elderfield and Rickaby's (2000) assertion for a Rayleigh-type fraction model than the simplistic two-slope kink model. Together these observations, in particular our analysis of $\mathrm{Co}: \mathrm{PO}_{4}^{3-}$ ratios, suggest that the excess metal:P stoichiometry mechanism may be an important contributor in metal:phosphate kink formation in the oceans.

The proximity of the nutricline to the surface in high nutrient low chlorophyll regions is particularly conducive to both the excess metal uptake and iron-limitation mechanisms for metal:phosphate kink formation. This presents a concern with the premise of an iron-limitation mechanism for $\mathrm{Cd}$ kink formation, in the degree to which the global dissolved $\mathrm{Cd}: \mathrm{P}$ database biases against datasets from shallower depths of the low nutrient low chlorophyll regions (LNLC). While nitrate and phosphate accumulate in surface waters in the iron limited regions due to upwelling, they exist at very low concentrations in surface waters of the subtropical gyres (Wu et al., 2000). This feature could prevent the excess metal uptake mechanism from occurring in the subtropical gyres where $\mathrm{Cd}, \mathrm{Zn}$, and phosphate are all very low in abundance due to the long vertical diffusion/advection distances prior to entering the euphotic zone. Low abundances may test the uptake capabilities of phytoplankton transporters and prevent excess $\mathrm{Cd}$ and $\mathrm{Zn}$ uptake (fractionation) relative to phosphate from occuring. This suggests that the excess metal uptake mechanism could provide an alternate mechanism for observations of $\mathrm{Cd}$ :P kinks occurring primarily in the iron-limited oceanic regions. However, a profile from coastal waters in the Bering Sea was shown to be consistent with the ironlimitation mechanism, where iron and macronutrient replete waters did not show a Cd:PO $\mathrm{PO}_{4}^{3-}$ kink (Cullen, 2006). It would be useful for future studies to examine the influence of ocean circulation processes on metal:phosphate relationships to differentiate between the contribution of these two mechanisms.

One curiousity related to metal:phosphate kinks is the presence of a convex dissolved $\mathrm{Cd}: \mathrm{PO}_{4}^{3-}$ relationship in the subarctic Pacific data of Martin et al. (1989; Fig. 9f). This phenomenon is also evident in the dissolved $\mathrm{Cd}: \mathrm{PO}_{4}^{3-}$ ratios that occur between 100-250 $\mathrm{m}$ that are higher than deep water values (Fig. 11d), suggesting an accumulation of $\mathrm{Cd}$ at those depths. We suspect this phenomenon is caused by the trifecta of relatively shallow remineralization of sinking particulate organic matter, a small inventory of dissolved cadmium at that depth, and regional upwelling that resupplies micronutrients to the surface. This mechanism is the same as the "biological concentrating mechanism" that we argued causes small but distinct peaks of dCo in the upper water column $(\sim 100 \mathrm{~m})$ within a mesoscale cyclonic eddy, coincident with the depth of significant particulate organic matter remineralization (Noble et al., 2008). The subarctic Pacific $\mathrm{Zn}: \mathrm{PO}_{4}^{3-}$ data (Fig. 11c; Martin et al., 1989) is 
consistent with this line of reasoning, where at the $\mathrm{Cd}: \mathrm{PO}_{4}^{3-}$ maximum $(150 \mathrm{~m})$, the dissolved $\mathrm{Zn}: \mathrm{PO}_{4}^{3-}$ also shows an increase relative to depths above and below it (green symbols in Fig. $11 \mathrm{c}, \sim 120 \mu \mathrm{mol} \mathrm{mol}^{-1}$ higher than at $200 \mathrm{~m}$ ). This $\mathrm{Zn}: \mathrm{PO}_{4}^{3-}$ positive excursion is of a similar absolute magnitude $\left(\sim 100 \mu \mathrm{mol} \mathrm{mol}{ }^{-1}\right.$ for both $\mathrm{Zn}: \mathrm{PO}_{4}^{3-}$ and $\left.\mathrm{Cd}: \mathrm{PO}_{4}^{3-}\right)$, but a much smaller relative magnitude in comparison to the large deepwater inventory of $\mathrm{Zn}$ (and P) that effectively masks this process. The strong euphotic zone $\mathrm{Zn}$ depletion that occurs (Fig. 11c) likely results in enhanced Cd use as suggested by Sunda and Huntsman (1995). Shallow recycling with continued upwelling could then concentrate $\mathrm{Cd}: \mathrm{P}$ in both dissolved (Fig. 11d) and particulate phases to create the elevated dissolved $\mathrm{Cd}: \mathrm{PO}_{4}^{3-}$ stoichiometry. The lack of such a convex $\mathrm{Cd}: \mathrm{PO}_{4}^{3-}$ relationship in the Ross Sea might be related to the lack of a continual upwelling supply source and the higher bioavailability of $\mathrm{Zn}$, which would decrease

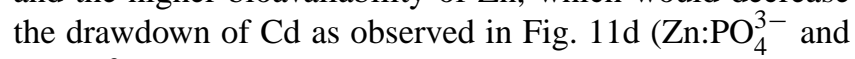
$\mathrm{Cd}: \mathrm{PO}_{4}^{3-}$ both reach lower ratios in the subarctic Pacific surface waters than the Ross Sea).

Together these observations are consistent with an emerging picture of high latitude environments that are supplied by upwelled nutrient and metal-rich $(\mathrm{Zn}, \mathrm{Cd})$ waters with $\mathrm{Zn}$ nutrition being of primary importance relative to Co. The large differences in the deepwater inventories of $\mathrm{Zn}, \mathrm{Cd}$, and Co span more than two orders of magnitude, 7580:606:38 relative to $\mathrm{PO}_{4}^{3-}$ respectively in the Ross Sea (Tables 1 and 2; Fig. 11b, c, d). This dynamic range appears to play a major role in influencing both their vertical distributions and their ecological stoichiometries, as described in the sections above. This situation is in contrast to tropical/subtropical regimes, where deeper nutriclines and/or an enhanced supply of cobalt from oxygen minimum zones appear to have much larger impacts on the ecological stoichiometry of Co (Table 1). These results are also consistent with observations that Chaetoceros calcitrans, an algal species related to those abundant in sea ice, lacks the ability to substitute Co for $\mathrm{Zn}$ (Timmermans et al., 2001), where the significant concentrations of bioavailable $\mathrm{Zn}$ would obviate the need for cambialistic biochemical substitution of $\mathrm{Co}$ for $\mathrm{Zn}$ in the austral spring prior to the seasonal depletion of nutrients and micronutrients.

\subsection{Lack of cobalt scavenging in the mesopelagic of the Ross Sea}

An unusual characteristic of Co geochemistry in the Ross Sea is the apparent lack of removal of dissolved Co from waters below the euphotic zone. This process, generally termed scavenging, can be caused by abiotic particle adsorbtion or biotic Mn co-oxidation (Tebo et al., 1984; Lee and Tebo, 1994; Moffett and Ho, 1996). As mentioned above, Co, Fe, $\mathrm{Mn}$ and $\mathrm{Cu}$, are all considered to be "hybrid-type" elements because their oceanic distributions are thought to be affected by both nutrient-like biological uptake and scavenging removal. A lack of scavenging removal for Co in the Ross Sea is evident in the vertical profiles from the summer and spring cruises (Figs. 3 and 4), which show no appreciable decrease in dissolved Co concentrations with depth, even to a depth of $\sim 800 \mathrm{~m}$ (station NX10). Scavenging removal of cobalt is typically observed at mesopelagic depths (Martin et al., 1989; Saito and Moffett, 2002; Noble et al., 2008), as seen for example in Fig. 9c from the subarctic Pacific. The lack of scavenging in the Ross Sea is reflected in the dissolved $\mathrm{Co}: \mathrm{PO}_{4}^{3-}$ relationship that is maintained throughout the water column (Fig. 6a). In contrast, scavenging removal is clearly apparent in the subarctic Pacific, where the $\mathrm{Co}: \mathrm{PO}_{4}^{3-}$ relationship breaks down below the euphotic zone creating a "cobalt curl" downward in Co versus $\mathrm{PO}_{4}^{3-}$ space, as scavenging removes dissolved Co without stoichiometric removal of $\mathrm{PO}_{4}^{3-}$ as shown in Figs. 9d and 7. We hypothesize that the lessened role of scavenging removal of Co in the Ross Sea is due to a lack of Mn oxidizing activity (and hence lack of co-oxidation of Co), due to the low concentrations of Mn in Southern Ocean waters (Martin et al., 1990; Sedwick et al., 2000). This is consistent with previous findings that Co oxidation rates are more sensitive to temperature decreases than Mn oxidation rates (Lee and Fisher, 1993). Alternatively (or additionally), the lack of observed scavenging may be related to the Ross Sea's seasonal winter deep mixing (Gordon et al., 2000): for scavenging to successfully imprint itself on cobalt distributions here, the process must occur on timescales of less than a year. These observations show that cobalt behaves as a "nutrient-like" element rather than a "hybrid-type" element in the Ross Sea. Further research into the apparent cause of low Co scavenging in the Ross Sea may illuminate other oceanic settings where Co may have a solely nutrient-like behavior. For example, if sea-ice extent was greatly expanded during the last glacial maximum, as suggested by Elderfield and Rickaby (2000), the extent of the oceans where the effects of Co scavenging was absent may also have expanded, potentially increasing regional or oceanic cobalt inventories.

\subsection{Potential applications of cobalt as a paleooceanographic proxy}

The comparative analysis of $\mathrm{Co}, \mathrm{Cd}$, and $\mathrm{Zn}$ ecological stoichiometries is useful in understanding their modern biological and geochemical processes. Given the importance of the $\mathrm{Cd}: \mathrm{PO}_{4}^{3-}$ relationship for paleooceanographic studies, it seems that significant insight could also be gained by adding Co, similar to the addition of $\mathrm{Zn}$ (Marchitto et al., 2000), to foraminiferal $\mathrm{Cd} / \mathrm{Ca}$ measurements. In particular, the lack of a kink in the $\mathrm{Co}: \mathrm{PO}_{4}^{3-}$ relationship could provide an ability to constrain the potential influence of aeolian dust deposition in creating an iron-limitation effect on the $\mathrm{Cd}: \mathrm{PO}_{4}^{3-}$ and $\mathrm{Zn}: \mathrm{PO}_{4}^{3-}$ relationship, providing some constraint on $\mathrm{P}$ 
proxies. While the variable $\mathrm{Co}: \mathrm{PO}_{4}^{3-}$ slopes described above (Sect. 3.5, Table 1) would make the application of Co as a proxy distinct from that of $\mathrm{Cd}$, this difference could be a strength providing information about changes in community micronutrient nutrition. In this sense, foraminiferal studies of $\mathrm{Zn}, \mathrm{Cd}$, and Co incorporation into tests may not only have utility as proxies for $\mathrm{P}$, but also as valuable proxies for the elements $\mathrm{Zn}, \mathrm{Cd}$, and Co themselves, which are of increasing interest for their influence on community composition. The measurement of this trio of metals in preserved biominerals may provide insight into not only the oceanic phosphate inventory, but also changes in phytoplankton species composition, regional signals of upwelling in oxygen minimum zones (e.g., Co, Saito et al., 2004), and perhaps Southern Ocean sea-ice cover (Co; through effects on scavenging), although further study is needed to constrain these signals in the modern ocean.

\section{Conclusions}

In this study of Co geochemistry in the Ross Sea, we observed a strong seasonal biological influence and a lack of scavenging removal on vertical structure. Together, these processes served to define the spatial and temporal distributions of cobalt in the category of nutrient-like, in contrast to previous observations of hybrid-type behavior (nutrientand scavenged-type) elsewhere in the oceans. Labile Co was measured in significant concentrations throughout the Ross Sea, suggesting a diminished source of Co-binding ligands and a correspondingly high biological availability of dissolved Co relative to other oceanic regions. The linkage between bioactive metals and phytoplankton appears strong in the Ross Sea, and a comparison of the ecological stoichiometries of $\mathrm{Zn}$ and Co suggests that $\mathrm{Zn}$ is likely influencing diatom diversity. No clear $\mathrm{Co}: \mathrm{PO}_{4}^{3-}$ kink was observed in the vertical profile datasets, leading to the hypothesis that observed $\mathrm{Zn}: \mathrm{PO}_{4}^{3-}$ and $\mathrm{Cd}: \mathrm{PO}_{4}^{3-}$ kinks present there are caused by the confluence of their much higher inventories compared to Co and the resultant excess metal stoichiometric uptake by phytoplankton. Finally, if the nutrient-like behavior of Co throughout the Ross Sea water column is caused by decreased Co scavenging rather than solely by annual deep mixing, it suggests that there may have been instances during Earth history where Co scavenging was similarly diminished, for example by expanded sea-ice cover or decreased Mn aeolian deposition, possibily leading to regional increases in $\mathrm{Co}$ inventories.

Acknowledgements. We thank the Captain, crew, and marine technicians of the Nathanial B. Palmer for their support during the CORSACS cruises. We also thank the CORSACS science team for helpful discussions and contributions to this program. We are indebted to Bettina Sohst for nutrient analyses, and Maeve Lohan, Angie Milne, Chris Marsay, Anna Aguilar-Islas and Juliette Tria for assistance with sample collection. We thank Ken Bruland and
Geoffrey Smith for fabricating the towfish underway sampling system. We thank Peter Croot, Michael Ellwood, and an anonymous reviewer for helpful comments on the manuscript. This research was supported by the US National Science Foundation through research grants (OPP-0440840, OPP-0338097, OPP-0732665, OCE-0452883, OCE-0752991, OCE-0928414).

Edited by: J. Middelburg

\section{References}

Arrigo, K. R., Worthen, D., Schnell, A., and Lizotte, M. P.: Primary Production in Southern Ocean waters, J. Geophys. Res, 103, 15587-15600, 1998.

Arrigo, K. R., Robinson, D. H., Worthen, D. L., Dunbar, R. B., DiTullio, G. R., VanWoert, M., and Lizotte, M. P.: Phytoplankton Community Structure and the Drawdown of Nutrients and $\mathrm{CO}_{2}$ in the Southern Ocean, Science, 283, 365-367, 1999.

Arrigo, K. R., van Dijken, G., and Long, M.: Coastal Southern Ocean: A strong anthropogenic $\mathrm{CO}_{2}$ sink, Geophys. Res. Lett., 35, L21602, doi:21610.21029/22008GL035624., 2008.

Baars, O. and Croot, P. L.: The speciation of dissolved Zinc in the Atlantic sector of the Southern Ocean, Deep-Sea Res. Pt. II, doi:10.1016/j.dsr2.2010.10.041, in press, 2010.

Bertilsson, S., Berglund, O., Karl, D. M., and Chisholm, S. W.: Elemental composition of marine Prochlorococcus and Synechococcus: Implications for ecological stoichiometry of the sea, Limnol. Oceanogr., 48, 1721-1731, 2003.

Bertrand, E. M., Saito, M. A., Rose, J. M., Riesselman, C. R., Lohan, M. C., Noble, A. E., Lee, P. A., and DiTullio, G. R.: Vitamin $\mathrm{B}_{12}$ and iron co-limitation of phytoplankton growth in the Ross Sea, Limnol. Oceanogr., 52, 1079-1093, 2007.

Bertrand, E. M., Saito, M. A., Jeon, Y. J., and Neilan, B. A.: Vitamin $\mathrm{B}_{12}$ biosynthesis gene diversity in the Ross Sea: the identification of a new group of polar $\mathrm{B}_{12}$-biosynthesizers, Environ. Microbiol., in press, 2011.

Boyle, E. A.: Cd: chemical tracer of deep-water paleooceanography, Paleooceanogr., 3, 471-489, 1988.

Boyle, E. A., Sclater, F. R., and Edmond, J. M.: On the marine geochemistry of cadmium, Nature, 263, 42-44, 1976.

Boyle, E., Huested, S., and Jones, S.: On the Distribution of Copper, Nickel, and Cadmium in the Surface Waters of the North Atlantic and North Pacific Ocean, J. Geophys. Res., 86, 8048-8066, 1981.

Bruland, K. W.: Oceanographic distributions of cadmium, zinc, nickel and copper in the North Pacific, Earth Planet. Sc. Lett., 47, 176-198, 1980.

Bruland, K. W.: Complexation of zinc by natural organic ligands in the central North Pacific, Limnol. Oceanogr., 34, 269-285, 1989.

Bruland, K. W.: GEOTRACES Co Intercalibration Results, http://www.obs-vlfr.fr/GEOTRACES/libraries/documents/ Intercalibration/SAFe_Co.pdf, 2010.

Bruland, K. W. and Lohan, M. C.: Controls of Trace Metals in Seawater, Treatise on Geochemistry, edited by: Elderfield, H., Elsevier Science Ltd, Cambridge, 2003.

Bruland, K. W., Rue, E. L., Smith, G. J., and DiTullio, G. R.: Iron, macronutrients and diatom blooms in the Peru Upwelling regime: Brown and blue waters of Peru, Mar. Chem., 93, 81-103 2005. 
Campbell, L., Nolla, H. A., and Vaulot, D.: The importance of Prochlorococcus to community structure in the central North Pacific Ocean, Limnol. Oceanogr., 39, 954-961, 1994.

Capodaglio, G., Turetta, C., Toscano, G., Gambaro, A., Scarponi, G., and Cescona, P.: Cadmium, lead and copper complexation in Antarctic coastal seawater, Evolution during the austral summer Internat, J. Environ. Anal. Chem., 71, 195-226, 1998.

Caron, D. A., Dennett, M. A., Lonsdale, D. J., Moran, D. M., and Shalapyonok, L.: Microzooplankton herbivory in the Ross Sea, Antarctica, Deep-Sea Res Pt. II, 47, 3249-3272, 2000.

Coale, K. H., Wang, X., Tanner, S. J., and Johnson, K. S.: Phytoplankton growth and biological response to iron and zinc addition in the Ross Sea and Antarctic Circumpolar Current along $170^{\circ} \mathrm{W}$, Deep-Sea Res. Pt. II, 50, 635-653, 2003.

Coale, K. H., Michael Gordon, R., and Wang, X.: The distribution and behavior of dissolved and particulate iron and zinc in the Ross Sea and Antarctic circumpolar current along $170^{\circ} \mathrm{W}$, DeepSea Res. Pt. I, 52, 295-318, 2005.

Cochlan, W. P., Bronk, D. A., and Coale, K. H.: Trace metals and nitrogenous nutrition of Antarctic phytoplankton: experimental observations in the Ross Sea, Deep-Sea Res. Pt. II, 49, 33653390, 2002.

Corami, F., Capodaglio, G., Turetta, C., Soggia, F., Magi, E., and Grotti, M.: Summer distribution of trace metals in the western sector of the Ross Sea, Antarctica, J. Environ. Monitor., 7, 12561264, 2005.

Croft, M. T., Lawrence, A. D., Raux-Deery, E., Warren, M. J., and Smith, A. G.: Algae require vitamin $\mathrm{B}_{12}$ through a symbiotic relationship with bacteria, Nature, 438, 90-93, 2005.

Croot, P. L., Baars, O., and Streu, P.: The distribution of dissolved Zinc in the Atlantic sector of the Southern Ocean, Deep-Sea Res. Pt. II, 2010, in press, 2010.

Cullen, J. T.: On the Nonlinear Relationship between Dissolved Cadmium and Phosphate in the Modern Global Ocean: Could Chronic Iron Limitation of Phytoplankton Growth Cause the Kink?, Limnol. Oceanogr., 51, 1369-1380, 2006.

Cullen, J. T. and Sherrell, R. M.: Effects of dissolved carbon dioxide, zinc, and manganese on the cadmium to phosphorus ratio in natural phytoplankton assemblages, Limnol. Oceanogr., 50, 1193-1204, 2005.

Cullen, J. T., Chase, Z., Coale, K. H., Fitzwater, S. E., and Sherrell, R. M.: Effect of iron limitation on the cadmium to phosphorus ratio of natural phytoplankton assemblages from the Southern Ocean, Limnol. Oceanogr., 48, 1079-1087, 2003.

de Baar, H. J. W.: von Liebig's Law of the Minimum and Plankton Ecology (1899-1991), Prog. Oceanogr., 33, 347-386, 1994.

de Baar, H. J. W., Saager, P. M., Nolting, R. F., and van der Meer, J.: Cadmium versus phosphate in the world ocean, Mar. Chem., 46, 261-281, 1994.

DiTullio, G. R. and Geesey, M. E.: Photosynthetic pigments in marine algae and bacteria, in: The Encyclopedia of Environmental Microbiology, edited by: Bitton, G., John Wiley \& Sons, Inc., New York, NY, 2453-2470, 2002.

DiTullio, G. R. and Smith Jr., W. O.: Spatial patterns in phytoplankton biomass and pigment distributions in the Ross Sea, J. Geophys. Res., 101, 18467-18477, 1996.

DiTullio, G., Grebmeier, J. M., Arrigo, K. R., Lizotte, M. P., Robinson, D. H., Leventer, A., Barry, J. P., VanWoert, M. L., and Dunbar, R. B.: Rapid and early export of Phaeocystis antarc- tica blooms in the Ross Sea, Antarctica, Nature, 404, 595-598, 2000.

DiTullio, G. R., Geesey, M. E., Jones, D. R., Daly, K. L., Campbell, L., and Smith Jr., W. O.: Phytoplankton assemblage structure and primary productivity along $170^{\circ} \mathrm{W}$ in the South Pacific Ocean, Mar. Ecol.-Prog. Ser., 255, 55-80, 2003.

Droop, M. R.: The nutrient status of algal cells in continuous culture, J. Mar. Biol. Assoc. UK, 54, 825-855, 1974.

Droop, M. R.: Vitamins, phytoplankton and bacteria: symbiosis or scavenging?, J. Phycol., 29, 107-113, 2007.

Ducklow, H., Carlson, C., Church, M., Kirchman, D., Smith, D., and Steward, G.: The seasonal development of the bacterioplankton bloom in the Ross Sea, Antarctica, 1994-1997, Deep-Sea Res. Pt. II, 48, 4199-4221, 2001.

Elderfield, H. and Rickaby, R. E. M.: Oceanic Cd/P ratio and nutrient utilization in the glacial Southern Ocean, Nature, 405, 305$310,2000$.

Ellwood, M. J.: Wintertime trace metal ( $\mathrm{Zn}, \mathrm{Cu}, \mathrm{Ni}, \mathrm{Cd}, \mathrm{Pb}$ and Co) and nutrient distributions in the Subantarctic Zone between 40-52 ${ }^{\circ}$ S; 155-160 E, Mar. Chem., 112, 107-117, 2008.

Ellwood, M. J. and van den Berg, C. M. G.: Determination of organic complexation of cobalt in seawater by cathodic stripping voltammetry, Mar. Chem., 75, 33-47, 2001.

Ellwood, M. J., van den Berg, C. M. G., Boye, M., Veldhuis, M., de Jong, J. T. M, de Baar, J. W., Croot, P. L., and Kattner, G.: Organic complexation of cobalt across the Antarctica Polar Front in the Southern Ocean, Mar. Freshwater Res., 56, 1069-1075, 2005.

Fitzwater, S. E., Johnson, K. S., Gordon, R. M., Coale, K. H., and Smith, W. O.: Trace metal concentrations in the Ross Sea and their relationship with nutrients and phytoplankton growth, Deep-Sea Res. Pt. II, 47, 3159-3179, 2000.

Frew, R. D. and Hunter, K. A.: Influence of Southern Ocean waters on the cadmium-phosphate properties of the global ocean, Nature, 360, 144-146, 1992.

Frew, R. D. and Hunter, K. A.: Cadmium-phosphorus cycling at the subtropical convergence south of New Zealand, Mar. Chem., 51, 223-237, 1995.

Giovannoni, S. J., Tripp, J., Givan, S., Podar, M., Vergin, K. L., Baptista, D., Bibbs, L., Eads, J., Richardson, T. H., Noordewier, M., Rappé, M. S., Short, J. M., Carrington, J. C., and Mathur, E. J.: Genome Streamlining in a Cosmopolitan Oceanic Bacterium, Science, 309, 1242-1245, 2005.

Gobler, C., Norman, C., Panzeca, C., Taylor, G., and SanudoWilhelmy, S.: Effect of B-vitamins $\left(\mathrm{B}_{1}, \mathrm{~B}_{12}\right)$ and inorganic nutrients on algal bloom dynamics in a coastal ecosystem, Aquat. Microb. Ecol., 49, 181-194, 2007.

Gordon, G. T. and Sullivan, C. W.: Vitamin $\mathrm{B}^{12}$ and cobalt cycling among diatoms and bacteria in Antarctica sea ice microbial communities, Limnol. Oceanogr., 53, 1862-1877, 2008.

Gordon, L. I., Jennings Jr., J. C., Ross, A. A., and Krest, J. M.: A Suggested Protocol for Continuous Flow Automated Analysis of Seawater Nutrients (Phosphate, Nitrate, Nitrite and Silicic Acid) in the WOCE Hydrographic Program and the Joint Global Ocean Fluxes Study, 1-55, 1993.

Gordon, L. I., Codispoti, L. A., Jennings, J. C., Millero, F. J., Morrison, J. M., and Sweeney, C.: Seasonal evolution of hydrographic properties in the Ross Sea, Antarctica, 1996-1997, Deep-Sea Res. Pt. II, 47, 3095-3117, 2000. 
Grotti, M., Soggia, F., Ianni, C., and Frache, R.: Trace metals distributions in coastal sea ice of Terra Nova Bay, Ross Sea, Antarctica, Antarct. Sci., 17, 289-300, 2005.

Heggie, D. and Lewis, T.: Cobalt in pore waters of marine sediments, Nature, 311, 453-455, 1984.

Hendry, K. R., Rickaby, R. E. M., Hoog, J. C. M. d., Weston, K., and Rehkamper, M.: Cadmium and phosphorus in coastal Antarctic seawater: Implications for Southern Ocean nutrient cycling, Mar. Chem., 112, 149-157, 2008.

Hendry, K. R., Rickaby, R. E. M., Hoog, J. C. M. d., Weston, K., and Rehkamper, M.: The cadmium-phosphate relationship in brine: biological versus physical control over micronutrients in sea ice environments, Antarct. Sci., 22, 11-18, 2009.

Ho, T.-Y., Quigg, A., Finkel, Z. V., Milligan, A. J., Wyman, K., Falkowski, P. G., and Morel, F. M. M.: The Elemental Composition Of Some Marine Phytoplankton, J. Phycol., 39, 1145-1159, 2003.

Jakuba, R. W., Saito, M. A., Moffett, J. W., Bidigare, B., and Xu, Y.: Dissolved Zinc in the North Pacific: Distribution, specication, and importance to primary producers, Global Biogeochem. Cy., in press, 2011.

Lane, T. W. and Morel, F. M. M.: Regulation of carbonic anhydrase expression by zinc, cobalt, and carbon dioxide in the marine diatom Thalassiosira weissflogii, Plant Physiol., 123, 1-8, 2000.

Lane, T. W., Saito, M. A., George, G. N., Pickering, I. J., Prince, R. C., and Morel, F. M. M.: A cadmium enzyme from a marine diatom, Nature, 435, p. 42, 2005.

Lane, E. S., Jang, K., Cullen, J. T., and Maldonado, M. T.: The interaction between inorganic iron and cadmium uptake in the marine diatom Thalassiosira oceanica, Limnol. Oceanogr., 53, 1784-1789, 2008.

Lane, E. S., Semeniuk, D. M., Strzepek, R. F., Cullen, J. T., and Maldonado, M. T.: Effects of iron limitation on intracellular cadmium of cultured phytoplankton: Implications for surface dissolved cadmium to phosphate ratios, Mar. Chem., 115, 155-162, 2009.

Lee, B.-G. and Fisher, N.: Microbially meditated cobalt oxidation in seawater revealed by radiotracer experiments, Limnol. Oceanogr., 38, 1593-1602, 1993.

Lee, Y. and Tebo, B.: Cobalt(II) Oxidation by the Marine Manganese(II)-Oxidizing Bacillus sp. Strain SG-1, Appl. Environ. Microbio., 60, 2949-2957, 1994.

Marchitto, T. M., Curry, W. B., and Oppo, D. W.: Zinc concentrations in benthic foraminfera reflect seawater chemistry, Paleooceanogr., 15, 299-306, 2000.

Marinov, I., Gnanadesikan, A., Toggweiler, J. R., and Sarmiento, J. L.: The Southern Ocean biogeochemical divide, Nature, 441, 964-967, 2006.

Martin, J. H., Gordon, R. M., Fitzwater, S., and Broenkow, W. W.: VERTEX: phytoplankton/iron studies in the Gulf of Alaska., Deep-Sea Res., 36, 649-680, 1989.

Martin, J. H., Fitzwater, S. E., and Gordon, R. M.: Iron Deficiency Limits Phytoplankton Growth in Antarctic Waters, Global Biogeochem. Cy., 4, 5-12, 1990.

McMinn, A., Skerratt, J., Trull, T., Ashworth, C., and Lizotte, M.: Nutrient stress gradient in the bottom $5 \mathrm{~cm}$ of fast ice, McMurdo Sound, Antarctica, Polar Biol., 21, 220-227, 1999.

Moffett, J. W. and Ho, J.: Oxidation of cobalt and manganese in seawater via a common microbially catalyzed pathway, Geochim.
Cosmochim. Ac., 60, 3415-3424, 1996.

Morel, F. M. M., Reinfelder, J. R., Roberts, S. B., Chamberlain, C. P., Lee, J. G., and Yee, D.: Zinc and carbon co-limitation of marine phytoplankton, Nature, 369, 740-742, 1994.

Noble, A. E., Saito, M. A., Maiti, K., and Benitez-Nelson, C.: Cobalt, manganese, and iron near the Hawaiian Islands: A potential concentrating mechanism for cobalt within a cyclonic eddy and implications for the hybrid-type trace metals, Deep-Sea Res Pt. II, 55, 1473-1490, 2008.

Nozaki, Y.: A Fresh Look at Element Distribution in the North Pacific, EOS, http://www.agu.org/eos_elec/97025e.html, 1997.

Orsi, A. H. and Weiderwohl, C. L.: A recount of Ross Sea waters, Deep-Sea Res. Pt. II, 56, 778-795, 2009.

Orsi, A. H., Smethie Jr., W. M., and Bullister, J. L.: On the total input of Antarctic waters to the deep ocean: A preliminary estimate from chlorofluorocarbon measurements, J. Geophys. Res., 107, 3122 doi:3110.1029/2001JC000976, 2002.

Panzeca, C., Tovar-Sanchez, A., Agusti, S., Reche, I., Duarte, C. M., Taylor, G. T., and Sanudo-Wilhelmy, S. A.: B Vitamins as Regulators of Phytoplankton Dynamics, EOS T. Am. Geophys. Un., 87, p. 593, 2006.

Redfield, A. C., Ketchum, B. H., and Richards, F. A.: The influence of organisms on the composition of seawater, in: The Composition of Seawater, edited by: Hill, M. N., The Sea, Vol. 2, Wiley, New York, 26-77, 1963.

Roberts, S., Lane, T., and Morel, F. M. M.: Carbonic anhydrase in the marine diatom Thalassiosira weissflogii (Bacillariophyceae), J. Phycol., 33, 845-850, 1997.

Rodionov, D. A., Vitreschak, A. G., Mironov, A. A., and Gelfand, M. S.: Comparative Genomics of the Vitamin $\mathrm{B}_{12}$ Metabolism and Regulation in Prokaryotes, J. Biol. Chem., 278, 4114841159, 2003.

Saager, P. M. and de Baar, H. J. W.: Limitations to the quantitative application of $\mathrm{Cd}$ as a paleoceanographic tracer, based on results of a multi-box model and statistical considerations, Global Planet. Change, 8, 69-92, 1993.

Saito, M. A. and Goepfert, T. J.: Zinc-cobalt colimitation in Phaeocystis antarctica, Limnol. Oceanogr., 53, 266-275, 2008.

Saito, M. A. and Moffett, J. W.: Complexation of cobalt by natural organic ligands in the Sargasso Sea as determined by a new highsensitivity electrochemical cobalt speciation method suitable for open ocean work, Mar. Chem., 75, 49-68, 2001.

Saito, M. A. and Moffett, J. W.: Temporal and spatial variability of cobalt in the Atlantic Ocean, Geochim. Cosmochim. Ac., 66, 1943-1953, 2002.

Saito, M. A. and Schneider, D. L.: Examination of precipitation chemistry and improvements in precision using the $\mathrm{Mg}(\mathrm{OH})_{2}$ preconcentration ICP-MS method for high-throughput analysis of open-ocean $\mathrm{Fe}$ and $\mathrm{Mn}$ in seawater, Anal. Chim. Acta, 565, 222-233, 2006.

Saito, M. A., Moffett, J. W., Chisholm, S. W., and Waterbury, J. B.: Cobalt limitation and uptake in Prochlorococcus, Limnol. Oceanogr., 47, 1629-1636, 2002.

Saito, M. A., Moffett, J. W., and DiTullio, G.: Cobalt and Nickel in the Peru Upwelling Region: a Major Flux of Cobalt Utilized as a Micronutrient, Global Biogeochem. Cy., 18, GB4030, doi:10.1029/2003GB002216, 2004.

Saito, M. A., Rocap, G., and Moffett, J. W.: Production of cobalt binding ligands in a Synechococcus feature at the Costa Rica 
Upwelling Dome, Limnol. Oceanogr., 50, 279-290, 2005.

Saito, M. A., Goepfert, T. J., and Ritt, J. T.: Some thoughts on the concept of colimitation: three definitions and the importance of bioavailability, Limnol. Oceanogr., 53, 276-290, 2008.

Sañudo-Wilhelmy, S. A., Gobler, C. J., Okbamichael, M., and Taylor, G. T.: Regulation of phytoplankton dynamics by vitamin $\mathrm{B}_{12}$, Geophys. Res. Lett., 33, L04604, doi:10.1029/2005GL025046, 2006.

Sedwick, P. N. and DiTullio, G. R.: Regulation of algal blooms in Antarctic Shelf Waters by the release of iron from melting sea ice, Geophys. Res. Lett., 24, 2515-2518, doi:10.1029/97g102596, 1997.

Sedwick, P. N., DiTullio, G. R., and Mackey, D. J.: Iron and manganese in the Ross Sea, Antarctica: Seasonal iron limitation in Antarctic shelf waters, J. Geophys. Res, 105, 11321-11336, 2000.

Sedwick, P. N., Sholkovitz, E. R., and Church, T. M.: Impact of anthropogenic combustion emissions on the fractional solubility of aerosol iron: Evidence from the Sargasso Sea, Geochem. Geophy. Geosy., 8(10), Q10Q06, doi:10.1029/2007GC001586, 2007.

Sedwick, P. N., Marsay, C. M., Aguilar-Islas, A. M., Lohan, M. C., Sohst, B. M., Long, M. C., Arrigo, K. R., Bruland, K. W., DiTullio, G. R., Dunbar, R. B., Saito, M. A., and Smith, W. O.: Early-season iron depletion in the Ross Sea polynya: Implications for iron dynamics on the Antarctic continental shelf, J. Geophys. Res., in press, 2011.

Smith, J. W. O., Shields, A. R., Peloquin, J. A., Catalano, G., Tozzi, S., Dinniman, M. S., and Asper, V. A.: Interannual variations in nutrients, net community production, and biogeochemical cycles in the Ross Sea, Deep-Sea Res Pt. II, 53, 815-833, 2006.

Sterner, R. W. G. and Elser, J. J.: Ecological Stoichiometry: The Biology of Elements from Molecules to the Biosphere, Princeton University Press, Princeton NJ, 439 pp., 2002.

Sunda, W. and Huntsman, S. A.: Feedback interactions between zinc and phytoplankton in seawater, Limnol. Oceanogr., 37, 2540, 1992.
Sunda, W. G. and Huntsman, S. A.: Cobalt and Zinc interreplacement in marine phytoplankton: biological and geochemical implications, Limnol. Oceanogr., 40, 1404-1417, 1995.

Sunda, W. G. and Huntsman, S. A.: Effect of Zn, Mn, and Fe on $\mathrm{Cd}$ accumulation in phytoplankton: Implications for oceanic $\mathrm{Cd}$ cycling, Limnol. Oceanogr., 45, 1501-1516, 2000.

Taylor, S. R. and McLennan, S. M.: The Continental Crust: its Composition and Evolution, Geoscience Texts, edited by: Hallam, A., Blackwell Scientific Publications, Boston, 1985.

Tebo, B., Nealson, K., Emerson, S., and Jacobs, L.: Microbial meditation of $\mathrm{Mn}$ (II) and $\mathrm{Co}(\mathrm{II})$ precipitation at the $\mathrm{O}_{2} / \mathrm{H}_{2}$ interfaces in two anoxic fjords, Limnol. Oceanogr., 29, 1247-1258, 1984.

Thuróczy, C.-E., Boye, M., and Losno, R.: Dissolution of cobalt and zinc from natural and anthropogenic dusts in seawater, Biogeosciences, 7, 1927-1936, doi:10.5194/bg-7-1927-2010, 2010.

Timmermans, K. R., Snoek, J., Gerringa, L. J. A., Zondervan, I., and de Baar, H. J. W.: Not all eucaryotic algae can replace zinc with cobalt: Chaetoceros calcitrans (Bacillariophyceae) versus Emiliania huxleyi (Prymnesiophyceae), Limnol. Oceanogr., 46, 699-703, 2001.

Whitfield, M. and Turner, D. R.: The role of particles in regulating the composition of sea-water, Aquatic Surface Chemistry, edited by: Stumm, W., Wiley-Intersci., 457-493, 1987.

Wong, G., Pai, S., and Chung, S.: Cobalt in the Western Philippine Sea, Oceanol. Acta, 18, 631-638, 1995.

Wu, J., Sunda, W., Boyle, E. A., and Karl, D. M.: Phosphate Depletion in the Western North Atlantic Ocean, Science, 289, 752762, 2000.

Zapata, M., Rodriguez, F., and Garrido, J. L.: Separation of chlorophylls and carotenoids from marine phytoplankton: a new HPLC method using a reversed phase $\mathrm{C}_{8}$ column and pyridinecontaining mobile phases, Mar. Ecol.-Prog. Ser., 195, 29-45, 2000 . 